\title{
Quantitative Models for Centralised Supply Chain Coordination
}

\author{
Mohamad Y. Jaber and Saeed Zolfaghari \\ Department of Mechanical and Industrial Engineering \\ Ryerson University, Toronto, ON, \\ Canada
}

\section{Introduction}

A supply chain is defined as a network of facilities and distribution options that perform the functions of procurement of materials, transformation of these materials into intermediate and finished products, and the distribution of these finished products to customers. Managing such functions along the whole chain; that is, from the supplier's supplier to the customer's customer; requires a great deal of coordination among the players in the chain. The effectiveness of coordination in supply chains could be measured in two ways: reduction in total supply chain costs and enhanced coordination services provided to the end customer - and to all players in the supply chain.

Inventory is the highest cost in a supply chain accounting for almost $50 \%$ of the total logistics costs. Integrating order quantities models among players in a supply chain is a method of achieving coordination. For coordination to be successful, incentive schemes must be adopted. The literature on supply chain coordination have proposed several incentive schemes for coordination; such as quantity discounts, permissible delay in payments, price discounts, volume discount, common replenishment periods.

The available quantitative models in supply chain coordination consider up to four levels (i.e., tier-1 supplier, tier-2 supplier, manufacturer, and buyer), with the majority of studies investigating a two-level supply chain with varying assumptions (e.g., multiple buyers, stochastic demand, imperfect quality, etc). Coordination decisions in supply chains are either centralized or decentralized decision-making processes. A centralized decision making process assumes a unique decision-maker (a team) managing the whole supply chain with an objective to minimize (maximize) the total supply chain cost (profit), whereas a decentralized decision-making process involves multiple decision-makers who have conflicting objectives.

This chapter will review the literature for quantitative models for centralised supply chain coordination that emphasize inventory management for the period from 1990 to end of 2007. In this chapter, we will classify the models on the basis of incentive schemes, supply chain levels, and assumptions. This chapter will also provide a map indicative of the limitations of the available studies and steer readers to future directions along this line of research. 


\section{Centralised supply chain coordination}

A typical supply chain consists of multistage business entities where raw materials and components are pushed forward from the supplier's supplier to the customer's customer. During this forward push, value is gradually added at each entity in the supply chain transforming raw materials and components to take their final form as finished products at the customer's end, the buyer. These business entities may be owned by the same organization or by several organizations.

Goyal \& Gupta (1989) suggested that coordination could be achieved by integrating lotsizing models. However, coordinating orders among players in a supply chain might not be possible without trade credit options, where the most common mechanisms are quantity discounts and delay in payments.

There are available reviews in the literature on coordination in supply chains. Thomas \& Griffin (1996) review the literature addressing coordinated planning between two or more stages of the supply chain, placing particular emphasis on models that would lend themselves to a total supply chain model. They defined three categories of operational coordination, which are vendor-buyer coordination, production-distribution coordination and inventory-distribution coordination. Thomas \& Griffin (1996) reviewed models targeting selection of batch size, choice of transportation mode and choice of production quantity. Maloni \& Benton (1997) provided a review of supply chain research from both the qualitative conceptual and analytical operations research perspectives. Recently, Sarmah et al. (2006) reviewed the literature dealing with vendor-buyer coordination models that have used quantity discount as coordination mechanism under deterministic environment and classified the various models. Most recently, Li \& Wang (2007) provided a review of coordination mechanisms of supply chain systems in a framework that is based on supply chain decision structure and nature of demand. These studies lacked a survey of mathematical models so the reader may detect the similarities and differences between different models. This chapter does so and updates the literature.

The body of the literature on coordinating order quantities between entities (level) in a supply chain focused on a two-level supply chain for different assumptions. A two-level supply chain could consist of a single vendor and a single buyer, or of a single vendor and multiple buyers. Few works have investigated coordination of orders in a three-level (supplier $\rightarrow$ vendor $\rightarrow$ buyer) supply chain, and described by paucity those works that assumed four levels (tier-2 suppliers $\rightarrow$ tier- 1 suppliers $\rightarrow$ vendor $\rightarrow$ buyer) or more.This chapter will classify the models by the number of levels, and therefore, there are three main sections. Section 3 reviews two-level supply chain models. Three-level models are discussed in section 4. Models with four or more levels are discussed in section 5.

\section{Two-level supply chain models}

The economic order quantity (EOQ) model has been the corner stone for almost all the available models in the literature. In a two-level chain, with coordination, the vendor (e.g., manufacturer, supplier) and the buyer optimize their joint costs.

\section{The basics}

Consider a vendor (manufacturer) and a buyer who each wishes to minimize its total cost. A basic model assumes the following: (1) instantaneous replenishment, (2) uniform and 
constant demand, (3) single non-perishable product of perfect quality, (5) zero lead time, and (6) infinite planning horizon.

The buyer's unit time cost function is given as

$$
T C_{b}(Q)=\frac{A_{b} D}{Q}+h_{b} \frac{Q}{2}
$$

The optimal order quantity that minimizes (1) is $Q^{*}=\sqrt{2 A_{b} D / h_{b}}$, where $A_{b}$ is the buyer's order cost,$h_{b}$ is the buyer's holding cost per unit per unit time, and $D$ is the demand rate per unit time and assumed to be constant and uniform over time. Substituting $Q^{*}$ in (1), then (1) reduces to $T C_{b}^{*}=\sqrt{2 A_{b} D h_{b}}$. The vendor's unit time cost function is given as

$$
T C_{v}(\lambda)=\frac{A_{v} D}{\lambda Q}+h_{v} \frac{Q}{2}(\lambda-1)
$$

Where $A_{v}$ is the vendor's order (setup) cost, $h_{v}$ is the vendor's holding cost per unit per unit time, and $\lambda$ being the vendor lot-size multiplier (positive integer) of the buyer's order quantity $Q$.

\section{From the buyer's perspective}

If the buyer is the supply chain leader, then it orders $Q^{*}$ every $T^{*}=Q^{*} / D$ units of time. Accordingly, the vendor treats $Q^{*}$ as an input parameter and finds the optimal $\lambda$ that minimizes its unit time cost, where $T C_{v}\left(\lambda^{*}-1\right)>T C_{v}\left(\lambda^{*}\right)<T C_{v}\left(\lambda^{*}+1\right)$. For this case, the vendor is the disadvantaged player. An approximate closed form expression is possible by assuming (2) to be differentiable over $\lambda$, then the optimal value of $\lambda$ is given as

$$
\lambda^{*}=\frac{1}{Q^{*}} \sqrt{\frac{2 A_{v} D}{h_{v}}}=\sqrt{\frac{2 A_{v} D}{h_{v}} \times \frac{h_{b}}{2 A_{b} D}}=\sqrt{\frac{A_{v} h_{b}}{A_{b} h_{v}}}
$$

For example, if the $\lambda=2.58$, then $\lambda^{*}=2$ if $T C_{v}\left(\lambda^{*}=2\right)<T C_{v}\left(\lambda^{*}+1=3\right)$; otherwise, $\lambda^{*}=3$. The vendor may find the lot-for-lot $\left(\lambda^{*}=1\right)$ policy to be optimal if

$$
\frac{A_{v} D}{Q}<\frac{A_{v} D}{\lambda Q}+h_{v} \frac{Q}{2}(\lambda-1) \Rightarrow \frac{A_{v} D}{Q}\left(\frac{\lambda-1}{\lambda}\right)<h_{v} \frac{Q}{2}(\lambda-1) \Rightarrow \frac{A_{v} D}{Q \lambda}<h_{v} \frac{Q}{2} \Rightarrow \lambda>\frac{2 A_{v} D}{h_{v} Q^{2}} .
$$

From the vendor's perspective

The buyer's EOQ may not be optimal to the vendor. From a vendor's perspective, the optimal order quantity is given from differentiating (2) over $Q$ and solving for $Q$ to get

$$
Q^{* *}=\sqrt{\frac{2 A_{v} D}{h_{v} \lambda(\lambda-1)}}, \text { where } \lambda>1
$$

Then the optimal value of (2) as a function of $\lambda>1$ is given as 


$$
T C_{v}^{*}(\lambda)=\sqrt{\frac{2 A_{v} D h_{v}(\lambda-1)}{\lambda}}
$$

The optimal cost occurs when $T C_{v}^{*}\left(\lambda^{* *}-1\right)>T C_{v}^{*}\left(\lambda^{* *}\right)<T C_{v}^{*}\left(\lambda^{* *}+1\right)$. For this case, the buyer is the disadvantaged player. The ideal case would occur when the EOQ of the buyer matches that of the vendor, i.e., $Q^{*}=Q^{* *}$, where

$$
\begin{gathered}
\frac{A_{v}}{h_{v} \lambda(\lambda-1)}=\frac{A_{b}}{h_{b}} \Rightarrow \frac{A_{v} h_{b}}{A_{b} h_{v}}=\lambda(\lambda-1) \Rightarrow \lambda^{2}-\lambda-\frac{A_{v} h_{b}}{A_{b} h_{v}}=0 \Rightarrow \lambda^{*}=\frac{1+\sqrt{1+4 A_{v} h_{b} / A_{b} h_{v}}}{2} \geq 2 \\
\Rightarrow \sqrt{1+4 A_{v} h_{b} / A_{b} h_{v}} \geq 3 \Rightarrow A_{v} h_{b} / A_{b} h_{v} \geq 2
\end{gathered}
$$

Vendor-buyer coordination

In many cases, there is a mismatch between the quantity ordered by the buyer and the one that the vendor desires to sell to the buyer. A joint replenishment policy would be obtained by minimizing the joint supply chain cost which is given as

$$
T C_{s c}(Q, \lambda)=T C_{b}(Q)+T C_{v}(\lambda)=\frac{A_{b} D}{Q}+h_{b} \frac{Q}{2}+\frac{A_{v} D}{\lambda Q}+h_{v} \frac{Q}{2}(\lambda-1)
$$

Goyal (1977) is believed to be the first to develop a joint vendor-buyer cost function as the one described in (6). Differentiating (6) over $Q$ and solving for $Q$ to get

$$
Q(\lambda)=\sqrt{\frac{2 D\left(\lambda A_{b}+A_{v}\right)}{h_{b} \lambda+h_{v} \lambda(\lambda-1)}}
$$

The order quantity in (7) is larger than the buyers EOQ for every $\lambda \geq 1$, which means higher cost to the buyer. This can be shown by setting $Q(\lambda)>Q^{*}$ to get $\left(\lambda A_{b}+A_{v}\right) /\left[h_{b} \lambda+h_{v} \lambda(\lambda-1)\right]>A_{b} / h_{b}$. Some researchers added a third cost component to the cost function in (6). For example, Woo et al. (2000) studied the tradeoff between the expenditure needed to reduce the order processing time and the operating costs identified in Hill (1997), by examining the effects of investment in EDI on integrated vendor and buyer inventory systems. Another example is the work of Yang \& Wee (2003) who incorporated a negotiation factor to balance the cost saving between the vendor and the buyer.

To make coordination possible, the vendor must compensate the buyer for its loss. This compensation may take the form of unit discounts and is computed as

$$
\begin{gathered}
d=\frac{T C_{b}(Q(\lambda))-T C\left(Q^{*}\right)}{D} \\
=A_{b} \sqrt{\frac{h_{b} \lambda+h_{v} \lambda(\lambda-1)}{2 D\left(\lambda A_{b}+A_{v}\right)}}+h_{b} \sqrt{\frac{\left(\lambda A_{b}+A_{v}\right)}{2 D\left[h_{b} \lambda+h_{v} \lambda(\lambda-1)\right]}}-\sqrt{\frac{2 h_{b} A_{b}}{D}}
\end{gathered}
$$

Crowther (1964) is believed to be the first who focused on quantity discounts from the buyer-seller perspective. For a good understanding of the precise role of quantity discounts 
and their design, readers may refer to the works of Dolan (1987) and Munson \& Rosenblatt (1998).

Recently, Zhou \& Wang (2007) developed a general production-inventory model for a single-vendor-single-buyer integrated system. Their model neither requires the buyer's unit holding cost be greater than the vendor's nor assumes the structure of shipment policy. Zhou \& Wang (2007) extended their general model to consider shortages occurring only at the buyer's end. Following, their production-inventory model was extended to account for deteriorating items. Zhou \& Wang (2007) identified three significant insights. First, no matter whether the buyer's unit holding cost is greater than the vendor's or not, they claimed that their always performs best in reducing the average total cost as compared to the existing models. Second, when the buyer's unit holding cost is less than that of the vendor's, the optimal shipment policy for the integrated system will only comprise of shipments increasing by a fixed factor for each successive shipment. Very recently, Sarmah et al. (2007) considered a coordination problem which involves a vendor (manufacturer) and a buyer where the target profits of both parties are known to each other. Considering a credit policy as a coordination mechanism between the two parties, the problem's objective was to divide the surplus equitably between the two parties.

In the following sections, we survey the studies that extended upon the basic vendor-buyer coordination problem (two-level supply chain) by relaxing some of its assumptions. The following sections are: (1) finite production rate, (2) non-uniform demand,(3) permissible delay in payments, (4) multiple buyers, (5) multiple Items, (6) product/process quality, (7) deterioration, (8) entropy cost and (9) stochastic models.

Finite production rate

Banerjee (1986) assumed finite production rate rather than instantaneous replenishment. He also assumed a lot-for-lot $(\lambda=1)$ policy. Banerjee's cost function which is a modified form of (6) is given as

$$
T C_{s c}(Q)=\frac{A_{b} D}{Q}+h_{b} \frac{Q}{2}+\frac{A_{v} D}{Q}+h_{v} \frac{D}{P} Q
$$

Where $h_{b}=I c_{b}$ and $h_{v}=I c_{v}$ in which $c_{v}$ is the vendor's unit purchase (production) cost, $c_{b}$ is the buyer's unit purchase cost, $I$ is the carrying cost dollar per dollar, and $P$ is the manufacturer production rate $(P>D)$. The optimal order quantity that minimizes $(9)$ is given as

$$
Q^{*}=\sqrt{\frac{2 D\left(A_{b}+A_{v}\right)}{h_{b}+h_{v} \frac{D}{P}}}
$$

Goyal (1988) extended the work of Banerjee (1986) by relaxing the assumption of lot-for-lot policy. He suggested that (9) should be written as

$$
T C_{S C}(Q)=\frac{A_{b} D}{Q}+\left(h_{b}-h_{v}\right) \frac{Q}{2}+\frac{A_{v} D}{\lambda Q}+\frac{\lambda h_{v} Q}{2}\left(1+\frac{D}{P}\right)
$$

The optimal order quantity that minimizes (11) is given as 


$$
Q(\lambda)=\sqrt{\frac{2 D\left(A_{b}+\frac{A_{v}}{\lambda}\right)}{h_{b}-h_{v}+\lambda h_{v}\left(1+\frac{D}{P}\right)}}
$$

Joglekar \& Tharthare (1990) presented the refined JELS model which relaxes the lot-for-lot assumption, and separates the traditional setup cost into two independent costs. They proposed a new approach to the problem which they claim will require minimal coordination between the vendor and purchasers. They believed this approach, known as the individually responsible and rational decision (IRRD) approach allows the vendor and the purchasers to carry out their individually rational decisions. Very recently, Ben-Daya et al. (2008) provided a comprehensive and up-to-date review of the JELS that also provides some extensions of this important problem. In particular, a detailed mathematical description of, and a unified framework for, the main JELP models was provided.

Wu \& Ouyang (2003) determined the optimal replenishment policy for the integrated singlevendor single-buyer inventory system with shortage algebraically. This approach was developed by Grubbström \& Erdem (1999) who showed that the formula for the EOQ with backlogging could be derived algebraically without reference to derivatives. $\mathrm{Wu} \&$ Ouyang's (2003) integrated vendor-buyer total cost per year is given by

$$
T C_{s C}=\frac{A_{b} D}{Q}+h_{b} \frac{(Q-B)^{2}}{2 Q}+\pi_{b} \frac{B^{2}}{2 Q}+\frac{A_{v} D}{\lambda Q}+h_{v} \frac{Q}{2}\left[\lambda\left(1-\frac{D}{P}\right)+\frac{2 D}{P}-1\right]
$$

Where $B$ is the maximum shortage level for the buyer. The optimal solutions of $Q$ and $B$ are given as

$$
\begin{gathered}
Q(\lambda)=\sqrt{\frac{2 D\left(\pi_{b}+h_{b}\right)\left(A_{b}+\frac{A_{v}}{\lambda}\right)}{h_{b} \pi_{b}+h_{v}\left(\pi_{b}+h_{b}\right)\left[\lambda\left(1-\frac{D}{P}\right)+2 \frac{D}{P}-1\right]}} \\
B(\lambda)=\frac{h_{b}}{\pi_{b}+h_{b}} Q(\lambda)
\end{gathered}
$$

Where $\pi_{b}$ is the annual buyer's shortage cost per unit.

Ertogral et al. (2007) develop two new models that integrate the transportation cost explicitly in the single vendor single-buyer problem. The transportation cost was considered to be in an all-unit-discount format for the first model. Their supply chain cost function was of the form

$$
T C_{s c}=\frac{\left(A_{v}+\lambda A_{b}\right) D}{\lambda q}+h_{v}\left[q \frac{D}{P}+\frac{\lambda q}{2}\left(1-\frac{D}{P}\right)\right]+\left(h_{b}-h_{v}\right) \frac{q}{2}+C_{T}
$$

Where $C_{T}=c_{i D}$ is the transportation cost per unit of time and $C_{T}$ is a step-form function, where $q \in\left[M_{i}, M_{i+1}\right), i=0,1,2 \ldots, \lambda$, and $M_{0}=0$, and $q$ is the shipment lot size. 
Non-uniform demand

$\mathrm{Li}$ et al. (1995) considered the case where the buyer is in monopolistic position with respect to the vendor. They assumed the demand, $D=\alpha_{b} p_{b}^{-\beta}$, by the buyer's customers is a decreasing function of the buyer's price $p_{b}$, where $\alpha_{b}>0$ and $0<\beta<1$ that could be determined by some statistical technique from historical data. Li et al. (1995) assumed $p_{b}=k p$ where $p$ is the buyer purchase price and $k>0$, and rewriting the demand function as $D=\alpha p^{-\beta}$ where $\alpha=\alpha k^{-\beta}$. When the vendor and the buyer achieve full cooperation, the supply chain's total cost function is given

$$
T C_{S C}(p, Q)=\alpha(1-G) p^{1-\beta}+\alpha\left(A_{v}+A_{b}\right) \frac{p^{-\beta}}{Q}+\frac{h_{b}}{2} p Q
$$

Where $G$ is the vendor's gross profit on sales. The above cost function was minimized subject to $\alpha p^{1-\beta}+\alpha A_{b} p^{-\beta} / Q+h_{b} p Q / 2 \leq C_{0}, p>0$, and $Q>0$, where $C_{0}$ is the maximum available annual investment. Then the equilibrium point of the co-operative game is

$$
\begin{gathered}
p^{*}=\left\{\frac{\eta^{*}}{\alpha G}\left(C_{0}-\frac{\eta^{*} h_{b} A_{b}}{2\left(G-\eta^{*}\right)}\right)\right\}^{1 /(1-\beta)} \\
Q^{*}=\frac{2 \alpha\left(G-\eta^{*}\right)}{\eta^{*} h_{b}}\left(p^{*}\right)^{-\beta}
\end{gathered}
$$

Where $\eta^{*}=\frac{G\left(h_{b} A_{b}+2 C_{0}\right)-\sqrt{G\left(h_{b} A_{b}+2 C_{0}\right) h_{b}\left(G A_{b}+A_{v}\right)}}{h_{b} A_{b}+2 C_{0}}$

Boyaci \& Gallego (2002) analyzed coordination issues in a supply chain consisting of one vendor (wholesaler) and one or more buyers (retailers) under deterministic price-sensitive customer demand. They defined the total channel profits as

$$
\begin{gathered}
\Pi(w, \lambda, p, Q)=\left(p-c_{v}\right) D(p)-\left(\frac{A_{v}}{\lambda}+a_{v}+A_{b}\right) \frac{D(p)}{Q} \\
-\frac{1}{2}\left\{\left(I_{v} c_{v}+\theta_{v}\right) \lambda+\theta_{b}-\theta_{v}-\left|I_{b}-I_{v}\right| w\right\} Q
\end{gathered}
$$

Where $a_{v}$ is the vendor's fixed cost of processing a buyer's order, $\theta_{v}\left(\theta_{b}\right)$ is the vendor's (buyer's) opportunity cost of the space required to store one unit of the product for one year, $c_{v}$ is the vendor's unit ordering cost, and assumed to be known and constant, $w$ is a decision variable selected by the wholesaler, $D(p)$ is the demand rate seen by the buyer when the Buyer (retailer) price is $p$, and $I_{v}\left(I_{b}\right)$ the vendor's (buyer's) opportunity cost of capital per dollar per year. They investigated their model for the cases of inventory ownership $\left(I_{v}>I_{b}\right.$ or $\left.I_{v}<I_{b}\right)$, equal ownership $\left(I_{v}=I_{b}\right)$, and an arbitrage opportunity to make infinite profits $\left(I_{v} \neq I_{b}\right)$. 


\section{Permissible delay in payments}

Besides quantity discounts, permissible delay in payments is a common mechanism of trade credit that facilitates coordinating orders among players in a supply chain.

Jamal et al. (2000) assumed that the buyer can pay the vendor either at time some time $M$ to avoid the interest payment or afterwards with interest on the unpaid balance due at $M$. Typically, the buyer may not pay fully the wholesaler by time $M$ for lack of cash. On the other hand, his cost will be higher the longer the buyer waits beyond $M$. Therefore, the buyer will gradually pay the wholesaler until the payment is complete. Since the selling price is higher than the unit cost, and interest earned during the credit period $M$ may also be used to payoff the vendor, the payment will be complete at time $P$ before the end of each cycle $T$ (i.e., $M \leq P \leq T$ ). Jamal et al. (2000) modelled the vendor-buyer system as a cost minimization problem to determine the optimal payment time $P^{*}$ under various system parameters.

$$
\begin{gathered}
T C_{s c}(P, T)=\frac{A_{v}+A_{b}}{T}+\frac{c D}{\theta^{2} T}\left(e^{\theta T}-1\right)(\theta+I)-c D-\frac{I c D}{\theta}-\frac{c I_{p} D}{\theta^{2} T}\left(e^{\theta(T-P)}-e^{\theta(T-M)}\right) \\
-\frac{c I_{p} D}{\theta T}(P-M)-I_{p} D(s-c)\left(P^{2}-M^{2}\right) / 2 T \\
-I_{p} s I_{e} D M^{2}(P-M) / 2 T-s I_{e} D\left(M^{2}+(T-P)^{2}\right) / 2 T
\end{gathered}
$$

Where $I_{e}$ is the interest earned per dollar per unit time, $I_{p}$ the interest paid per dollar per unit time dollars/dollar-year, $I$ is the inventory carrying cost rate, $c$ is the unit cost, $s$ is the unit selling price, and $\theta$ is the deterioration rate, a fraction of the on-hand inventory. No closed form solution was developed, and an iterative search approach is employed simultaneously to obtain solutions for $P$ and T. Recently, Yang \& Wee (2006a) proposed a collaborative inventory model for deteriorating items with permissible delay in payment with finite replenishment rate and price-sensitive demand. A negotiation factor is incorporated to balance the extra profit sharing between the two players.

Abad \& Jaggi (2003) considered a vendor-buyer channel in which the end demand is price sensitive and the seller may offer trade credit to the buyer. The unit price seller charged by the seller and the length of the credit period offered by the vendor to the buyer both influence the final demand for the product. The paper provides procedures for determining the vendor's and the buyer's policies under non-cooperative as well as cooperative relationships. Here, we present the model for the cooperative case. Abad \& Jaggi (2003) used Pareto efficient solutions that can be characterized by maximizing (Friedman, 1986)

$$
Z=\mu\left[K p^{-e}\left(c_{b}-c_{v}-I_{v} c_{b} M-\frac{A_{v}}{Q}\right)\right]+(1-\mu)\left[K p^{-e}\left(p-c_{b}\left(1-I_{c} M\right)-\frac{A_{b}}{Q}\right)-\frac{I c_{b} Q}{2}\right]
$$

Where $D(p)=K p^{-e}$ is annual demand rate as a function of the buyer's price, $e$ the index of price elasticity, $M$ is the credit period (vendor's decision variable), $c_{b}$ the price charged by the vendor to the buyer, $c_{v}$ is the seller's unit purchase cost, $I_{c b}$ vendor's opportunity cost of capital, $I_{c}$ short-term capital cost for the buyer, $I_{b}$ inventory carrying charge per year 
excluding the cost of financing inventory, and $I=I_{C}+I_{b}$. The first order necessary condition for maximizing $Z$ with respect to $c_{b}$ yields

$$
0 \leq \mu=\frac{1-I_{\mathcal{C}} M+I Q /\left(2 K p^{-e}\right)}{2-I_{v} M-I_{\mathcal{C}} M+I Q /\left(2 K p^{-e}\right)} \leq 1
$$

First order conditions with respect to $Q$ and $M$ yield

$$
\begin{gathered}
Q=\sqrt{\frac{2 K p^{-e}\left[\mu A_{v}+(1-\mu) A_{b}\right]}{(1-\mu) I_{b}}} \\
M=\frac{(1-\mu) I_{c}-a \mu}{2 b \mu}
\end{gathered}
$$

where $I_{v}=a+b M, a>0, b>0$. Abad \& Jaggi (2003) cautioned that not all $\mu$ in the interval $[0,1]$ may yield feasible solutions.

Jaber \& Osman (2006) proposed a centralized model where players in a two-level (vendorbuyer) supply chain coordinate their orders to minimize their local costs and that of the chain. In the proposed supply chain model the permissible delay in payments is considered as a decision variable and it is adopted as a trade credit scenario to coordinate the order quantity between the two-levels. They presented the buyer and vendor unit time cost functions respectively as

$$
T C_{b}(Q, t, \tau)=\frac{A_{b} D}{Q}+c_{b} D+\frac{D}{Q} H_{b}(Q, t, \tau)+\frac{s_{b}}{2} Q+c_{b} D\left(e^{k_{v}(\tau-t)}-e^{k_{b} \tau}\right)
$$

where $H_{r}(Q, t, \tau)=h_{b}(Q-D t)^{2} / 2 D$ (Case I), or $h_{b}(Q-D \tau)^{2} / 2 D$ (Case II), or 0 (Case III). It should be clarified that the retailer must settle his/her balance, $c_{b} Q$, with the supplier either by time $t$ or by time $\tau$, which are respectively the interest-free and the interest permissible delay in payment periods, where $0 \leq H_{b}(Q, t, \tau) \leq h_{b} Q^{2} / 2 D$

$$
T C_{v}(Q, \lambda, t, \tau)=\frac{A_{v} D}{\lambda Q}+\frac{h_{v}+s_{v}}{2} Q(\lambda-1)+h_{v} \tau D+\left(c_{b}-c_{v}\right) D e^{k_{v} t}-c_{b} D e^{k_{v}(\tau-t)}+c_{v} D
$$

Define $t$ as the permissible delay in payment in time units, (interest-free period), and $\tau$ is the buyer's time to settle its account with the vendor. If $\tau>t$ the supplier charges interest for the period of $\tau-t$ (interest period). The other parameters are defined as follows (where $i=$ $v, b): k_{i}$, the return on investment, $h_{i}$ is holding cost per unit of time, representing the cost of capital excluding the storage cost, $s_{i}$ the storage cost per unit of time at level $i$ excluding the holding cost, and $c_{i}=$ Procurement unit cost for level $i=v, b$. With coordination, the buyer and the vendor need to agree on the following decision variables $Q, \lambda$, $t$, and $\tau$, that minimizes the total supply chain cost by solving the following mathematical programming model

Minimize $T C_{S C}(Q, \lambda, t, \tau)=T C_{v}(Q, \lambda, t, \tau)+T C_{b}(Q, t, \tau)$ 
Subject to:

$$
\begin{aligned}
& \tau-t \geq 0 \\
& \lambda \geq 1 \\
& Q / D-t \geq 0(\text { Case I), } Q / D-\tau \geq 0 \text { (Case II), } \tau-Q / D \geq 0 \text { (Case III) } \\
& t \geq 0, \tau \geq 0, \lambda=1,2,3, . ., \text { and } Q \geq 1
\end{aligned}
$$

Jaber \& Osman (2006) assumed profits (savings) from coordination to be shared between the buyer and the vendor in accordance with some prearranged agreement.

Chen \& Kang (2007) considered a similar model to that of Jaber \& Osman (2006), where they investigated their model for predetermined and extended periods of delay in payments. However, and unlike the work of Jaber \& Osman (2006), Chen \& Kang (2007) have not treated the length of delay in payment as a decision variable. Sheen \& Tsao (2007) consider vendor-buyer channels subject to trade credit and quantity discounts for freight cost. Their work determined the vendor's credit period, the buyer's retail price and order quantity while still maximizing profits. Sheen \& Tsao (2007) focused on how channel coordination can be achieved using trade credit and how trade credit can be affected by quantity discounts for freight cost. Like Chen \& Kang (2007), they set an upper and lower bounds on the length of the permissible delay in payments. They search for the optimal length of this credit from the vendor's perspective and not from that of the supply chain coordination.

Multiple buyers

Affisco et al. (1993) provided a comparative analysis of two sets of alternative joint lot-sizing models for the general one-vendor, many-nonidentical buyers' case. Specifically, the basic joint economic lot size (JELS) and individually responsible and rational decision (IRDD) models, and the simultaneous setup cost and order cost reduction versions are explored. The authors considered co-operation is required of the parties regardless of which model they choose to implement, it is worthwhile to investigate the possible impact of such efforts on the model. The joint total relevant cost on all buyers and the vendor is given by

$$
T C_{S C}=\sum_{i=1}^{n}\left\{\left(\frac{D_{i}}{Q_{i}}\right)\left(A_{b, i}+\alpha\right)+h_{b, i} \frac{Q_{i}}{2}\right\}+h_{v} \frac{Q_{v}}{2}\left(1-\frac{D}{P}\right)+A_{v} \frac{D}{Q_{v}}
$$

Where $\alpha$ is the vendor's cost of handling and processing an order from a purchaser. This included such costs as inspection, packing and shipping of an order, and the cost of any related paperwork, but not the cost of manufacturing setup to produce a production quantity. The refined JELS model results from minimizing TC which yields the following relationships for the vendor's and $i$ th buyer's joint optimal lot sizes are $Q_{v}^{*}=\sqrt{2 D A_{v} /\left(h_{v}(1-D / P)\right)}$, and $Q_{i}^{*}=\sqrt{2 D_{i}\left(A_{b, i}+\alpha\right) / h_{b, i}}$ respectively, where $D=\sum_{i=1}^{n} D_{i}$. Under the IRRD model, since a purchaser must pay for the vendor's handling costs every time it orders $O_{i}=\left(D_{i} / Q_{i}\right)\left(A_{b, i}+\alpha\right)$.The holding cost per unit per unit time is also reduced due to the transferred handling costs.

$\mathrm{Lu}(1995)$ considered an integrated inventory model with a vendor and multiple buyers. Lu assumed the case where the vendor minimizes its total annual cost subject to the maximum cost that the buyer may be prepared to incur. They presented a mixed integer programming problem of the form 


$$
\begin{gathered}
\text { Minimize } T C_{S C}\left(T, k_{i} \mid i=1, \ldots, n\right)=\frac{1}{T}\left(A_{v}+\sum_{i=1}^{n} \frac{A_{b, i}}{\max \left\{1, k_{i}\right\}}\right) \\
+\frac{T}{2} \sum_{i=1}^{n} \max \left\{1, k_{i}\right\} h_{b, i} D_{i}\left(1+\min \left\{1, k_{i}\right\}-\frac{D_{i}}{P_{i}}-\frac{2 m_{i}}{k_{i}}\right)
\end{gathered}
$$

Subject to

$$
\begin{gathered}
T \geq 0, \\
\frac{1}{2}\left(\frac{T_{i}^{*}}{k_{i} T}+\frac{k_{i} T}{T_{i}^{*}}\right) \leq B_{i} \\
k_{i} \in\{1,2,3, \ldots\} \cup\left\{\frac{1}{2}, \frac{1}{3}, \frac{1}{4}, \ldots\right\} \\
m_{i}=\left\lfloor k_{i}\left(1-D_{i} / P_{i}\right)\right\rfloor, i=1,2, \ldots, n
\end{gathered}
$$

Where $T_{i}^{*}=\sqrt{2 A_{b, i} /\left(h_{b, i} D_{i}\right)}, A_{b, i}, h_{b, i}$, and $D_{i}$ are respectively the optimal cycle time, order cost, holding cost, and demand for buyer $i$. $T$ is the order interval suggested by the vendor and $B_{i}>1$ is some threshold value. Lu (1995) considered a quantity discount schedules to maximize the vendor's total profit subject to the maximum cost that the buyer may be prepared to incur. Yao \& Chiou (2004) proposed an efficient heuristic which solves Lu's model by exploring its optimality structure. They observed that the vendor's optimal annual total cost function is a piece-wise convex curve with respect to the vendor's production setup interval. Yao \& Chiou (2004) proposed an effective heuristic that outperforms Lu's heuristic.

Goyal (1995) commented on the work of $\mathrm{Lu}$ (1995) and suggested a joint inventory cost function of the form

$$
T C_{s c}(k)=\frac{D\left(A_{v}+k A_{b}\right)(n-1)}{q_{1}\left(n^{k}-1\right)}+\frac{q_{1}}{2}\left(h_{b}+\frac{h_{v}}{k}\right) \frac{n^{k}+1}{n+1}
$$

Where $k$ is the number of shipments in which the entire lot of size $Q=q_{1}\left(n^{k}-1\right) /(n-1)$ is transported by the vendor to the buyer in shipments of size $q_{i}$, where $i=1,2, \ldots, k$. Assuming that the ratio between the $(i+1)$-st shipment and the $i$-th shipment is equal to $n$. For a particular value of $k$, the economic value of $q_{1}=q(k)$ and the minimum joint total annual costs are given respectively as

$$
q(k)=\sqrt{\frac{2 D\left(A_{v}+k A_{b}\right)\left(n^{2}-1\right)}{\left(n^{2 k}-1\right)\left(h_{b}+\frac{h_{v}}{2}\right)}}
$$




$$
T C_{s c}(q(k))=\sqrt{\frac{2 D\left(h_{b}+h_{v} / 2\right)(n-1)\left(n^{k}+1\right)\left(A_{v}+k A_{b}\right)}{(n+1)\left(n^{k}-1\right)}}
$$

The works of Lu (1995) and Goyal (1995) are further analyzed in Hill (1997) and Viswanathan (1998).

Chen et al. (2001) proposed a coordination model for a centralized two-echelon system whose profit function is given as

$$
\Pi=\sum_{i=1}^{n}\left[\left(p_{i}\left(D_{i}\right)-c_{v}-c_{b, i}\right) D_{i}-\Psi\left(D_{i}\right)-\frac{A_{b, i}}{T_{i}}-\frac{1}{2} h_{v} D_{i} \max \left\{T_{v}, T_{i}\right\}-\frac{1}{2} h_{b, i} D_{i} T_{i}\right]-\frac{A_{v}}{T_{v}}
$$

Where $p_{i}$ retail price charged by buyer $i, p_{i}\left(D_{i}\right)$ annual demand a decreasing function of the retail price, $c_{b, i}$ unit shipping cost to from the vendor to the buyer $\Psi\left(D_{i}\right)$ is the annual cost incurred by the vendor for managing buyer $i$ 's account with $\Psi(\cdot)$ being a nondecreasing and concave where $\Psi(0)=0, T_{i}$ is the replenishment interval for buyer $i$, and $T_{v}$ is the replenishment interval for the vendor.

Viswanathan \& Piplani (2001) proposed a supply chain model of coordinating supply chain inventories through the use of common replenishment epochs (CRE) or time periods. They considered a vendor and multiple buyers with a single product. With the CRE strategy, the vendor specifies that the buyers can only place orders at specific points in time. The vendor was assumed to insist that the replenishment interval for each buyers $i T_{i}^{*}$ should be an integer multiple of the common replenishment period $T=\lambda_{i} T_{i}^{*}$, where $\lambda_{i}$ is a positive integer. With the specification of the CRE, the buyers' flexibility is reduced and inventory costs increased. The vendor will need to provide a price discount $Z_{i}$ to compensate buyer $i$ for inventory cost increase. The problem of determining the $T$ and $Z$ for the vendor can then be formulated as follows

$$
\text { Minimize } T C_{S C}=\frac{A_{v}}{T}+\sum_{i=1}^{n}\left(D_{i} Z+\frac{a_{i}}{\lambda_{i} T}\right)
$$

Subject to:

$$
\begin{gathered}
D_{i} Z \geq \frac{A_{b, i}}{\lambda_{i} T}+h_{b, i} \lambda_{i} T-2(1-S) \sqrt{A_{b, i} h_{b, i}}, i=1, \ldots, n \\
T \in \mathbf{X} \\
\lambda_{i} \geq 1 \text { and integer, } i=1, \ldots, n
\end{gathered}
$$

Where $\mathbf{X}=\{1 / 365,1 / 52,2 / 52,1 / 12,2 / 12,1 / 4\}, a_{i}$ is the cost of processing the order of buyer $i, S$ being the percentage savings, and $D_{i} Z$ is the total dollar discount offered to buyer $i$. Further investigation of the work of Viswanathan \& Piplani (2001) is provided in Piplani \& Viswanathan (2004). 
Woo et al. (2001) extended upon the work of Woo et al. (2000) to account for the case of multiple buyers. They assumed that vendor and all buyers are willing to invest in reducing the ordering cost (e.g., establishing an electronic data interchange based inventory control system) in order to decrease their joint total cost. Woo et al. (2001) stressed that a major managerial implication from this ordering cost reduction is that the efforts to streamline and speedup transactions via the application of information technologies may result in a higher degree of coordination and automation among allied trading parties. Woo et al. (2001) also assume that shortages are not allowed for the vendor and that the information of buyers' replenishment decision parameters is available to the vendor. The joint total cost for the vendor and all the buyers per unit time is

$$
\begin{gathered}
T C_{S C}=K+\frac{1}{T}\left[\frac{A_{v}}{\lambda}+S_{v}+\sum_{i=1}^{n} T_{i}(K)\right]+\frac{T}{2}\left[u h_{v, m} \sum_{i=1}^{n} D_{i}\left(\lambda-1+\frac{\sum_{i=1}^{n} D_{i}}{P}\right)\right] \\
+\frac{h_{v, p}}{P} \sum_{i=1}^{n} D_{i}^{2}+\sum_{i=1}^{n} h_{b, i}\left(1-f_{i}\right)^{2} D_{i}+\sum_{i=1}^{n} L_{i} f_{i}^{2} D_{i}
\end{gathered}
$$

Where $K$ is expenditure per unit time to operate the planned ordering system between vendor and all buyers, which is a decision variable, and $T_{i}(K)$ is the planned ordering cost per buyer $i$ 's order, which is a strictly decreasing function of $K$ with $T_{i}(0)=T_{0, i}$ and $T_{i}\left(K_{0}\right)=0, T$ is the common cycle time for buyers, which is a decision variable, $u$ is usage rate of raw materials for producing each finished item, $h_{v, m}$ and $h_{v, p}$ are respectively the vendor's carrying cost per unit of raw materials and finished products, $h_{b, i}$ is the carrying cost per unit held per unit time for buyer $i, f_{i}$ is the fraction of backlogging time in a cycle for buyer $i$, which is a decision variable, and $L_{i}$ is the backlogging cost per unit backlogged per unit time for buyer $i$. Note that this paper assumes the vendor incurs ordering cost for raw material $A_{v}$ and a setup cost per production run for vendor $S_{v}$.

Recently, Yu et al. (2006) improved upon the work of Woo et al. (2001) by providing a lower or equal joint total cost as compared to the relaxation of their integral multiple material ordering cycle policy to a fractional-integral multiple material ordering cycle policy. More recently, Zhang et al. (2007) extended the work of Woo et al. (2001) by relaxing the assumption of a common cycle time for all buyers and the vendor.

Siajadi et al. (2006a,b) presented a methodology to obtain the Joint Economic Lot size in the case where multiple buyers are demanding one type of item from a single vendor. The shipment policy is found and a new model is proposed to minimize the joint total relevant cost (JTRC) for both vendor and buyer(s). Further it is shown that a multiple shipment policy is more beneficial than a single shipment policy considered by Banerjee (1986). The incurred saving is increasing as the total demand rate approaches the production rate. This means that as long as the first assumption is still satisfied, the better the production capacity is utilized, the greater the saving will be. Conversely, when the dominating cost is the transportation cost, the saving is decreasing as the numbers of shipment approach to one. 
Consequently, the new model becomes identical with the traditional model, as the numbers of shipment are equal to one.

Yang \& Wee (2006b) considered a pricing policy for a two-level supply chain with a vendor and multiple buyers. Three scenarios are discussed. The first scenario neglects integration and quantity discount. The second scenario considers the integration of all players without considering quantity discount. The last scenario considers the integration and the quantity discount of all players simultaneously. The total supply chain cost for scenario $i=1,2,3$ was of the form

$$
\begin{gathered}
T C_{s c, i}=\frac{D\left(A_{v}+\lambda_{i} a_{v}\right)}{\lambda_{i} \sum_{j=1}^{n} Q_{i, j}}+\frac{h_{v}}{2} \sum_{j=1}^{n} Q_{i, j}\left[\left(\lambda_{i}-1\right)\left(1-\frac{D}{P}\right)+\frac{D}{P}\right]+\sum_{j=1}^{n}\left(c_{b, 1, j}-c_{b, i, j}\right) D_{j} \\
+\sum_{j=1}^{n} \frac{D_{j} A_{b, j}}{Q_{i, j}}+\sum_{j=1}^{n} \frac{Q_{i, j} h_{b, i, j}}{2}-\sum_{j=1}^{n}\left(c_{b, 1, j}-c_{b, i, j}\right) D_{j}
\end{gathered}
$$

Where $D=\sum_{j=1}^{n} D_{j}$ total demand rate of all buyers with $D_{j}$ being the demand for buyer $j$, $A_{v}$ and $A_{b, j}$ are as defined earlier respectively the vendor's and buyer's $j$ order/setup costs, $a_{v}$ a fixed cost to process buyer's order of any size, $\lambda_{i}$ the number of deliveries from vendor to each buyer per cycle for scenario $i, Q_{i, j}$, the order quantity for buyer $j$ for scenario $i, h_{v}$ is the vendor's holding cost, $h_{b, i, j}$ is the buyer's holding cost for buyer $j$ for scenario $i$, and $c_{b, i, j}$ being the unit purchase cost for buyer $j$ for scenario $i$. Recently, Wee \& Yang (2007) proposed a very similar work to that of Yang and Wee (2006b), where they extended the work of Yang et al. (2007) to consider multiple buyers rather than a single buyer. They developed an optimal pricing and replenishment policy in a "leagile" (lean and agile) supply chain system for an integrated vendor-buyers system considering JIT concept and price reduction to the buyers for ordering larger quantity.

Yugang et al. (2006) considered a Vendor-Managed-Inventory (VMI) supply chain, which consists of one vendor (manufacturer) and multiple different buyers (retailers) with a single product. The vendor produces a single product with a limited production capacity and distributes it to its buyers. Each buyer buys the product from the manufacturer at wholesale price, and then sells it to the consumer market at a retail price. The buyer' markets are assumed to be dispersed and independent of each other. In the proposed supply chain, the vendor, as a leader, determines the wholesale price and inventory policy for the supply chain to maximize its own profit, and each retailer, as a follower, in turn takes the vendor's decision results as given inputs to determine the optimal retail prices to maximise its own profits. Along this line of research, Nachiappan et al. (2006) proposed a methodology to determine the common optimal price (contract and selling prices) that protects the profit of the buyer which is the main reason for the existence of partnership, for maximum channel profit in a two-echelon SC to implement VMI. 


\section{Multiple Items}

Kohli \& Park (1994) examined joint ordering policy in a vendor-buyer system as a method for reducing the transactions cost for multiple products sold by a seller to a homogeneous group of buyers. They found that efficient joint lot-sizes are independent of prices, and are supported by a range of average-unit prices that permit every possible allocation of the transactions-cost saving between the buyer and the seller. Kohli \& Park (1994) also found that product bundling supports efficient joint orders across products, just as a quantity discount supports efficient transactions for a single product.

Chen \& Chen (2005a) proposed both centralized and decentralized decision policies to analyze the interplay and investigate the joint effects of two-echelon coordination and multiproduct replenishment on reduction of total costs. The total joint cost was given as

$$
\begin{gathered}
\operatorname{TC}_{s c}\left(\left\{\lambda_{i}\right\}, T\right)=\frac{A_{b}}{T}+\sum_{i=1}^{k}\left[\frac{a_{b, i}}{T}+\frac{T}{2}\left(h_{b, i} D_{i}\right)\right] \\
+\frac{A_{v}}{T}+\sum_{i=1}^{k}\left[\frac{a_{v, i}}{T}+\frac{T}{2}\left(\frac{h_{v, i} D_{i}^{2}}{P_{i}}\right)+\frac{a_{r, i}}{\lambda_{i} T}+\frac{u_{i} h_{r, i} T}{2}\left(\frac{D_{i}^{2}}{P_{i}}+\left(\lambda_{i}-1\right) D_{i}\right)\right]
\end{gathered}
$$

Where $T$ is the common cycle, $T>0, D_{i}$ the demand rate of finished item $i, P_{i}$ the production rate of finished item $i$ produced by the vendor $\left(P_{i}>D_{i}\right), h_{b, i}$ is the inventory holding cost of finished item $i$ per unit time for the buyer, $h_{v, i}$ is the inventory holding cost of finished item $i$ per unit time for the vendor, $h_{r, i}$ the inventory holding cost of raw material for finished item $i$ per unit time for the vendor, $a_{b, i}$ the minor setup cost for adding finished item $i$ into the order for the buyer, $a_{v, i}$ the minor setup cost for adding finished item $i$ into the production schedule for the vendor, $a_{r, i}$ the ordering cost of raw material for finished item $i$ per lot for the vendor, $u_{i}$ usage rate of raw material for the end item $i$ produced by the manufacturer, and $k$ is the total number of items. The optimal integer multiple of the common replenishment cycle for the raw material, the optimal common replenishment cycle, and the optimal order quantity for each item are given respectively as

$$
T^{*}=\sqrt{\frac{\lambda_{i}^{*}=\left[-\frac{1}{2}+\frac{1}{2} \sqrt{1+\frac{8 a_{r, i}}{T^{2} u_{i} h_{r, i} D_{i}}}\right]}{2\left[A_{b}+A_{v}+\sum_{i=1}^{k}\left(a_{b, i}+a_{v, i}+\frac{a_{r, i}}{\lambda_{i}^{*}}\right)\right]}}
$$




$$
Q_{i}^{*}=\sqrt{\frac{2 D_{i}^{2}\left[A_{b}+A_{v}+\sum_{i=1}^{k}\left(a_{b, i}+a_{v, i}+\frac{a_{r, i}}{\lambda_{i}^{*}}\right)\right]}{\sum_{i=1}^{k}\left[h_{b, i} D_{i}+\frac{h_{v, i} D_{i}^{2}}{P_{i}}+u_{i} h_{r, i}\left(\frac{D_{i}^{2}}{P_{i}}+\left(\lambda_{i}^{*}-1\right) D_{i}\right)\right]}}
$$

Chen \& Chen $(2005 \mathrm{~b}, \mathrm{c})$ proposed several optimization models adopting the joint replenishment program and channel coordination practice for a three level inventory system. The main purpose behind these models is to investigate how they influence possible supply chain improvements. The works of Chen \& Chen $(2005 b, c)$ neither considered marketing stimulus into account, nor they assumed that the goods being imperishable for the period of production and selling. Furthermore, they dealt with cost-minimization supply chain design.

Chen \& Chen (2007) focused on an area of emerging research: managing a multi-product and multi-echelon supply chain which produces and sells deteriorating goods in the marketplace. They formulated four profit-maximization models by considering the effects of channel coordination and a joint replenishment program on the supply-side cost control, taking into account the effect of the pricing scheme on demand and revenue increment. In addition, a profit-sharing mechanism via target rebates has been proposed, leading to Pareto improvements among channel participants.

\section{Product/process Quality}

Huang (2002) investigated the model of Salameh and Jaber (2000) in an integrated vendorbuyer context, where imperfect items at the buyer's end are withdrawn from inventory as a single batch and sold at a discounted price.The total annual cost of the vendor-buyer

$$
\begin{gathered}
T C_{s c}(\lambda, Q)=\left\{\frac{\left(A_{v}+A_{b}\right) D}{\lambda Q}+\frac{F D}{Q}+(d+W) D+\frac{D Q\left(h_{b}-h_{v}\right)}{x}\right\} E\left[\frac{1}{1-\gamma}\right]-W D \\
+\left\{\frac{D Q}{P}+\frac{\lambda Q}{2}\left(1-\frac{D}{P}\right)\right\} h_{v}-\frac{D Q}{x}\left(h_{b}-h_{v}\right)+\frac{Q(1-E[\gamma])}{2}\left(h_{b}-h_{v}\right)
\end{gathered}
$$

Where $F$ is the transportation cost per delivery, $\gamma$ is the percentage of defective items whose probability density function is $f(y), x$ is the screening rate per unit $(x>D), d$ is the unit screening cost, and $W$ is the vendor's unit warranty cost of a defective item. The optimal order quantity that minimizes the above equation was given as

$$
Q(\lambda)=\sqrt{\frac{2 D\left[\frac{A_{v}+A_{b}}{\lambda}+F\right] E\left[\frac{1}{1-\gamma}\right]}{\left[\frac{2 D\left(h_{b}-h_{v}\right)}{x}\right]\left(E\left[\frac{1}{1-\gamma}\right]-1\right)+\left[\frac{2 D}{P}+\lambda\left(1-\frac{D}{P}\right)\right] h_{v}+(1-E[\gamma])\left(h_{b}-h_{v}\right)}}
$$

Khouja (2003a) considers a simple supply chain consisting of a vendor who produces a product and delivers it to a buyer who in turn sells it to the final customer. He assumed the lot size quality relationship to follow that of Porteus (1986). Porteus assumed the production process to be functioning perfectly at the start of production. With the production of each 
unit, the process may shift out-of-control with a constant known transition probability, and start producing all defective units. Once the process is out of control, it stays that way while the remainder of the lot is produced. The production system is restored to perfect quality when it is set up again. Porteus (1986) estimated the expected defectives per lot to be $\rho Q^{2} / 2$ , where $\rho$ is the probability of the process going out of control and $\rho$ is very small (Khouja, 2005). The expected total annual cost for the vendor and the buyer is

$$
T C_{s c}=\left(A_{b}+\frac{A_{v}}{\lambda}\right) \frac{D}{Q}+\left[h_{b}-h_{v}+h_{v} \lambda\left(1+\frac{D}{P}\right)\right] \frac{Q}{2}+\frac{1}{2} \rho \lambda Q D w
$$

Where $\lambda$ is, as defined earlier, the vendor's lot-size multiplier (positive integer) of the buyer's order quantity $Q$, and $w$ being the cost to rework a defective unit. Minimizing the expected total annual cost for the whole supply chain (i.e. joint optimization), then the optimality conditions are given by

$$
\begin{aligned}
& \lambda^{*}\left(\lambda^{*}-1\right) \leq \frac{\left(h_{b}-h_{v}\right) A_{v}}{A_{b}\left(D w \rho+(1+D / P) h_{v}\right)} \leq \lambda^{*}\left(\lambda^{*}+1\right) \\
& Q^{*}(\lambda)=\sqrt{\frac{2\left(\lambda A_{b}+A_{v}\right)}{\lambda\left[\lambda w \rho+h_{b} / D+(\lambda / P+(\lambda-1) / D) h_{v}\right]}}
\end{aligned}
$$

Khouja (2003a) also investigated his model for the cases when the vendor has a constant failure rate, and when demand is stochastic.

Similar to Huang (2002), Goyal et al. (2003) considered a two-level supply chain where there is a vendor and a buyer for a single product, where the number of perfect units is at least equal to the demand during the screening time and that the defective units are sold as a single batch at the end of the screening period (Salameh \& Jaber, 2000). Their expected annual cost was given as

$$
T C_{s c}(\lambda, Q)=\left(A_{v}+A_{b}+\lambda F\right) \frac{D}{Q}+\frac{Q}{2 \lambda}\left\{[1+(\lambda-2)(1-D / P)] h_{v}+\frac{h_{b}}{E[1 /(1-\gamma)]}\right\}
$$

Where $F$ is the transportation cost per shipment, $\gamma$ is the percentage of defective items, a random variable, and $E[1 /(1-\gamma)]=\int_{0}^{\infty} f(y) d y$ is the expected value with $f(y)$ being the probability density function of $\gamma$. The optimal order quantity that minimizes the above equation is

$$
Q(\lambda)=\sqrt{\frac{2 \lambda\left(A_{v}+A_{b}+\lambda F\right) D}{[1+(\lambda-2)(1-D / P)] h_{v}+h_{b} / E[1 /(1-\gamma)]}}
$$

A very similar model to that of Goyal et al (2003) was developed in Huang (2004). Siajadi et al. (2005) analysed scenario is that a single buyer (or a group of buyers), demand(s) a particular type of end/finished item where back-order is not allowed. The delivery of the finished item to the customer is based on multiple small deliveries of equal size, $Q$, instead of a lot-for-lot basis. They assumed that the production of the finished item will include the production of imperfect quality items, where $100 \%$ inspection is performed for each lot at a 
constant unit cost. They further assumed that a lot contains a percentage of defectives with a known probability distribution function where the defective items are reworked instantaneously at a cost and kept in stock. Reworked items are considered as-good-as-new. The total unit time supply chain cost was given as

$$
T C_{S C}=\frac{A_{v}+A_{v}^{\prime}+\sum_{i=1}^{k} a_{i} / \lambda_{i}}{T}+\frac{T}{2} D^{\prime}\left[\sum_{i=1}^{k} h_{i} u_{i}\left(\frac{D^{\prime}}{P}+\lambda_{i}-1\right)+h_{v}\left(\frac{D}{P}+E\right)\right]-\frac{q}{2} h_{v}
$$

where $A_{v}^{\prime}$ is the major setup cost for ordering raw materials for every cycle period, $a_{i}$ is the minor order (setup) cost for ordering each type of raw material, $T$ is the cycle time, $h_{i}$ the vendor's holding cost for raw material $i, u_{i}$ is usage rate of raw material for producing finished item $i, E$ represents the expected percentage of good items, $D^{\prime}$ is the actual demand rate considering the rejected items, $\lambda_{i}$ is the integer multiple of the basic cycle period for each replenished item, and $q$ is equal freight quantity of finished item to customers. The stationary points in the $T$ direction were found to occur when

$$
T=\sqrt{\frac{2\left(A_{v}+A_{v}^{\prime}+\sum_{i=1}^{k} a_{i} / \lambda_{i}\right)}{D^{\prime}\left[h_{v}(D / P+E)+\sum_{i=1}^{k} h_{i} u_{i}\left[D^{\prime} / P+\lambda_{i}-1\right]\right]}}
$$

Comeaux \& Sarker (2005) addressed the shortcomings within existing models that would result in implementation problems for practical and industrial applications. Specifically, the fraction conforming in the quality-adjusted optimal batch size model denominator is squared to accurately reflect the quality improved and set-up cost reduction model's effectiveness. They also expanded the joint economic lot size models to address the full range of $0-100 \%$ product quality inspections by multiplying the fraction inspected by the inspection cost. The authors added that these models were modified to account for the cost of scrap generation by separating the proportion of non-conforming product that requires disposal and multiplying that quantity by the disposal cost. Moreover, the effects of rejecting conforming product, as well as accepting non-conforming product, in the quality inspection processes were also addressed.

El Saadany \& Jaber (2008) investigated the work of Khouja (2005) in a centralized decision model where players in a two-level (vendor-buyer) supply chain coordinate their orders to minimize their local costs and that of the chain. Unlike Porteus (1986), Khouja (2005) assumed that if the process is interrupted to perform corrective action to restore the process back in control reduces the number of defects generated. This reduces reworks significantly but at an additional cost of increased minor setups. For this assumption, three possible behaviours, or cases, of the vendor's inventory level were depicted with corresponding cost models developed. Case 1 assumes that restoring the production process after delivering a lot to the buyer. Case 2, restoring the production process before delivering a lot to the buyer. Case 3, restoring the production process at any time. El Saadany and Jaber (2008) developed mixed integer nonlinear programming models to optimize coordination for the three cases. The mathematics for the three cases presented in El Saadany and Jaber (2008) are lengthy and therefore we refrain from presenting them herein. 


\section{Deterioration}

Lin \& Lin (2004) developed an integrated vendor-buyer model for the case of product deterioration, partial backordering and constant service level, where deterioration occurs at the buyer's side only. It was assumed that the vendor invests heavily to build facilities that keep product fresh and therefore no deterioration. They assumed that transportation time of goods is short.

Lin \& Lin (2007) were concerned with the collaboration between a supplier and a buyer and take into consideration the deterioration property and complete back-ordering. Their model is similar to that of Balkhi's (1999) but assuming the vendor is a manufacturer rather than a materials supplier, and thus the buyer is a retailer (customer), or wholesaler rather than a manufacturer.

\section{Entropy cost}

There is no doubt that the proper estimation of the EOQ model input parameters, which are the order cost, carrying (holding) cost and the demand rate, are essential for producing reliable results. However, properly estimating and monitoring these costs is often not an easy task. Furthermore, the order and holding costs are aggregated costs that often include those costs that can be estimated, and exclude those which are difficult to ascertain. For example, the order cost might include costs for transportation, loading and unloading, inspection, insurance, administrative time, etc. The holding cost can include opportunity cost of capital, and costs for storage, obsolescence, damage, deterioration, insurance, etc. Furthermore, the use of more environmentally friendly materials and manufacturing processes to reduce pollution and energy expenditure give rise to additional costs that may be difficult to estimate. To address this problem, Jaber et al. (2004) postulated accounting for an additional and unavoidable cost, which we refer to as the entropy cost, when analysing EOQ systems. They postulated that the behaviour of production systems very much resembles those of physical systems. Such a parallel suggests that improvements to production systems may be achievable by applying the first and second laws of thermodynamics to reduce system entropy (or disorder).

Jaber et al. (2004) modelled commodity flow (demand rate) as a heat flow. To illustrate and briefly, when a force is imposed on a system, the system goes through a change in its state and a certain flow ensues. If, in the production system, the price is changed (lowered) from its equilibrium value, then a flow of the commodity in question may ensue. The force is what is commonly called in economics a "market force". Thus it is postulated that there will be a flow of commodity between the system and its surroundings (e.g., from the retailer to the market) at the rate

$$
q(t)=-K\left(P(t)-P_{0}(t)\right)
$$

where $K$ represents the change in the flux for a change in the price of a commodity, and is measured in units per year per dollar, $P(t)$ is the firm's price function (analogous the system's temperature), and $P_{0}(t)$ is the equilibrium price function (analogous the surrounding's temperature). Note that at $t=0, P(0)$ and $P_{0}(0)$ register their highest values, while at $t=\tau, P(\tau)$ and $P_{0}(\tau)$ register their lowest values. The total demand in a cycle of length $T, d(T)$, is given from the above commodity flow equation as

$$
d(T)=\int_{0}^{T} q(t) d t=\int_{0}^{T}-K\left(P(t)-P_{0}(t)\right) d t
$$


where $d(T)$ is measured in units, and it represents the lot size quantity; i.e., $Q=D T$. Similarly, the total entropy generated in a cycle of length $T, \sigma(T)$, is given (from thermodynamics) as

$$
\sigma(T)=\int_{0}^{T} \dot{S}_{g e n}(t) d t=\int_{0}^{T} K\left(\frac{P(t)}{P_{0}(t)}+\frac{P_{0}(t)}{P(t)}-2\right) d t
$$

where $\sigma(T)$ is measured in the total entropy generated over $T$ (with $\dot{S}_{\text {gen }}(t)$ being the entropy generation rate) is measured in the same units as $K$. Then the entropy cost per cycle, $E(T)$, is given by dividing

$$
E(T)=\frac{d(T)}{\sigma(T)}=\frac{\int_{0}^{T}-K\left(P(t)-P_{0}(t)\right) d t}{K \int_{0}^{T}\left(\frac{P(t)}{P_{0}(t)}+\frac{P_{0}(t)}{P(t)}-2\right) d t}
$$

Jaber et al. (2006a) applied the concept of entropy cost in a two-level (vendor-buyer) supply chain to account for the hidden costs and difficult to estimate costs of an inventory system. They assumed a two-level supply chain with a finite planning horizon. In their model, a supplier's cycle has $\lambda$ retailer's cycles, where $\lambda$ is a positive integer. If the retailer orders $n$ times a year, then the vendor has $m$ replenishment cycles a year, where $m \lambda=n$ and $m$ like $\lambda$ is a positive integer. Since the vendor demand flow is a stepped function, the vendor's commodity flow is written as

$$
q_{v}(t)=-K_{v}\left(P_{v}(t)-P_{0, v}(t)\right)
$$

where $P_{v}(t)$ and $P_{0, v}(t)$ are respectively the vendor's commodity and equilibrium price functions, and $K_{v}$ is similar in definition to $K$ (later referred to by $K_{b}$ where the subscript $b$ indicate the buyer) where $K_{v}=-q_{v}(0) /\left(P_{v}(0)-P_{0, v}(0)\right)$. The entropy generated in the $j$ th vendor's cycle that has $\lambda$ buyer's cycles was given as

$$
\sigma_{v, j}(\lambda, n)=\sum_{i=1}^{\lambda} K_{v}\left\{\frac{P_{v}(t)}{P_{0, v}(t)}+\frac{P_{0, v}(t)}{P_{v}(t)}-2\right\}=\sum_{i=1}^{\lambda} K_{v}\left\{\frac{P_{v}(i, j, \lambda, n)}{P_{0, v}(i, j, \lambda, n)}+\frac{P_{0, v}(i, j, \lambda, n)}{P_{v}(i, j, \lambda, n)}-2\right\}
$$

where $i=1,2, \ldots, \lambda, j=1,2, \ldots, m$ and $T=\tau / n$. The entropy cost of the $j$ th vendor's cycle was given

$$
E_{v, j}(\lambda, n)=\frac{Q \lambda}{\sigma_{v, j}(\lambda, n)}
$$

The total supply chain cost is given as

$$
T_{s c}(\lambda, n)=n A_{b}+h_{b} \frac{D \tau^{2}}{2 n}+\sum_{j=1}^{n / \lambda} E_{b, j}(\lambda, n)+\frac{n}{\lambda} A_{v}+\frac{h_{v}}{2}(\lambda-1) D \frac{\tau^{2}}{n}+\sum_{j=1}^{n / \lambda} E_{v, j}(\lambda, n)
$$


$\underline{\text { Stochastic models }}$

Sharafali \& Co (2000) presented some stochastic models of cooperation between the supplier and the buyer. Their study showed that only the supplier benefits from such cooperation. Sharafali \& Co (2000) considered some cooperative strategies. These include the analysis of the impact of (1) price changes, (2) discount policies and (3) partial deliveries. They assumed there is a buyer or a retailer who orders from a supplier, demand at the buyer is random and is distributed as Poisson with mean rate $\mu$, instantaneous replenishment, non-zero but constant lead time, stock outs at the buyer are back-ordered, and the buyer follow $(R, Q)$ policy.

$$
T C_{s C}=\frac{\mu}{Q}\left(A_{b}+\frac{A_{v}}{\lambda}\right)+\frac{1}{Q} \int_{R}^{R+Q} U(y) d y+\frac{h_{v}}{2}(\lambda-1) Q
$$

Where $\mu$ is the mean demand rate at the buyer's end, Demand at the buyer is random and is distributed as Poisson with mean rate $\mu . U(y)$ is the rate at which the expected inventory costs accumulate at time $t+$ Lead-time.

Pan \& Yang (2002) presents an integrated inventory model with controllable lead time. The model is shown to provide a lower total cost and shorter lead time compared with those of Banerjee (1986) and Goyal (1988), and is useful for practical inventory problems. They assumed a demand $X$ during lead time $L$ follows a normal distribution with mean $\mu L$ and standard deviation $\sigma \sqrt{L}$, the lead time has $n$ components and these are crashed one component at a time starting with the one with the least crashing cost per unit time, and so on, and that the reorder point (ROP) equals the sum of the expected demand during lead time and the safety stock, where $R O P=\mu L+k \sigma \sqrt{L}$ and where $k$ is known as the safety factor

$$
\operatorname{ETC}_{S C}(Q, L, \lambda)=\frac{D}{Q}\left[A_{b}+\frac{A_{v}}{\lambda}+R(L)\right]+\frac{Q}{2}\left\{\left[\lambda\left(1-\frac{D}{P}\right)-1+\frac{2 D}{P}\right] h_{v}+h_{b}\right\}+h_{b} k \sigma \sqrt{L}
$$

Where $R(L)=c_{i}\left(L_{i-1}-L\right)+\sum_{j=1}^{i-1} c_{j}\left(b_{j}-a_{j}\right)$ is the lead time crashing cost, and $c_{i}$ is the crashing cost per unit time for lead time component $i$ with $a_{i}$ and $b_{i}$ being the minimum and maximum durations respectively, such that $\sum_{i=1}^{n} a_{i} \leq L \leq \sum_{i=1}^{n} b_{i}$. Building upon the work of Pan and Yang (2002), Pan and Yang (2008) proposed two fuzzy models. The first model incorporates the fuzziness of annual demand, while the second accounts for fuzziness in production and demand rates. Recently, Hoque (2007) developed an alternative model of the problem with equal or unequal sized batches transfer under controllable lead time for a JIT system. He then developed a heuristic solution algorithm of the model and showed cost reduction in comparison with Pan \& Yang (2002) by solving the same numerical example solved by them. Srinivas \& Rao (2007) developed a controllable-lead-time inventory model where the lead time is assumed to be dependent because at the time of contract with a vendor (manufacturer), the buyer (retailer) may intend to reduce the lead time, for which he will pay an additional cost to accomplish an increased production rate.

Ben-Daya \& Hariga (2004) considered the single vendor single buyer integrated production inventory problem where demand is stochastic and the lead time is varying linearly with the 
lot size; i.e., $L(Q)=\kappa Q+\zeta$. The integrated vendor buyer expected total cost per unit time is given by

$$
\begin{gathered}
E T C_{s c}(Q, r, \lambda)=\frac{D}{Q}\left(F+\frac{A_{v}+A_{b}}{\lambda}\right)+\pi_{b} \zeta(r, L(Q)) \frac{D}{Q} \\
+\frac{Q}{2}\left\{h_{b}+h_{v}[\lambda(1-D \kappa)-1+2 D \kappa]\right\}+h_{b} S S_{b}
\end{gathered}
$$

where $\kappa=1 / P, \zeta$ denotes a fixed delay due to transportation, production etc, $F$ transportation cost for the buyer incurred with each shipment of size $Q, \pi_{b}$ and $S S_{b}$ are respectively the stock-out cost and safety stock at the buyer's end, $r$ the reordering level, and the remaining parameters are as defined earlier in this chapter.

The authors assumed that demand during lead time is normally distributed with mean $D L(Q)$ and standard deviation $\sigma \sqrt{L(Q)}$, where

$$
\begin{gathered}
S S_{b}=k \sigma \sqrt{\kappa Q+\zeta} \\
\zeta(r, L(Q))=\int_{s}^{\infty}(x-s) f(x, D L(Q), \sigma \sqrt{L(Q)}) d x \\
k=(r-D L(Q)) / \sigma \sqrt{L(Q)}
\end{gathered}
$$

Wee et al. (2006) proposed a production-inventory model for an on-going deterioration item with partial backordering and imperfect quality, with shortages due to imperfect items are completely backordered. This is because not all customers are willing to wait for a new replenishment of stock. Customers encountering shortages will respond differently according to the type of commodities and market environment. The expected value of the joint total cost was given as

$$
\begin{aligned}
& E T C_{S C}=\left[\frac{R}{\lambda T}-(D E[\rho]+D)-\left(\frac{E[p] \theta D^{2}}{x}+\frac{\theta D}{2} E\left[(1-\rho)^{2}\right]\right) T-\frac{E[\rho] \theta^{2} D^{3}}{2 x^{2}} T^{2}\right] \\
& \times\left(\frac{h_{v}}{\theta}+d_{v}\right)+\frac{A_{v}}{\lambda T}+\frac{A_{d}}{T}+\frac{A_{b}}{T}+\left(c_{b}+c_{x}+d_{b}+\frac{h_{b}}{\theta}\right) \times \\
& {\left[D E[p]+D+\left(\frac{\theta D^{2} E[\rho]}{x}+\frac{\theta D E\left[(1-\rho)^{2}\right]}{2}\right) T+\frac{\theta^{2} D^{3} E[\rho]}{2 x^{2}} T^{2}\right]} \\
& -\left(d_{b}+\frac{h_{b}}{\theta}\right)(D E[\rho]+D)+\frac{\pi_{b} D T}{2} E\left[\rho^{2}\right]
\end{aligned}
$$

Where $R$ is the total production quantity, $T$ is the buyer's cycle time, $D$ is the demand rate, $\theta$ is the deterioration rate, $x$ is the screening rate, $\rho$ is the defective percentage which has a 
uniform distribution over $\left[\rho_{0}, \rho_{1}\right], A_{d}$ is the delivery cost, $c_{b}$ the unit purchase cost per unit for the buyer, $d_{v}$ is the deterioration cost per unit for the vendor, $d_{b}$ is the deterioration cost per unit for the buyer, $c_{x}$ is the screening cost per unit for the buyer and $\pi_{b}$ is backordering cost per unit for the buyer.

Ritvirool \& Ferrell (2007) modelled a single-vendor, single-buyer purchasing system in which the buyer uses a $(Q, r)$ inventory policy and the vendor determines the production lot size on a make-to-order basis. They developed a cost based model that is used to determine the optimal order quantity and reorder point as well as the safety stock levels for both the vendor and buyer. The cost of quality is included by assuming that the vendor's inventory contains defective items. The total annual cost, $T C_{S C}(Q, r)$, the total expected cost per cycle is given as

$$
\begin{gathered}
T C_{s c}(Q, r)=h_{v}\left(r-\frac{Q D}{2 P}-S S_{b}\right)+h_{b}\left(\frac{Q}{2}+S S_{b}\right)+\left(A_{v}+A_{b}\right) \frac{D}{Q} \\
+D\left(c_{p}+c_{I}\right)+\left(c_{p}+c_{I}+d-v\right) \frac{D \delta \mu Q}{2 P}+\pi_{b} n(r) \frac{D}{Q}
\end{gathered}
$$

Where $\pi_{b}$ is the buyer's shortage cost, $\pi_{b} n(r)$ is cost associated with back ordering, $1 / \mu$ is the mean of the time $\tau$ when the production process shifts from in-control to out-of-control, $c_{p}$ is the unit production cost, $c_{I}$ is the unit inspection cost, an out-of-control process will result in $\delta \times 100 \%$ of the units being non-conforming and requiring replacement, $N$ is the number of defective per cycle where $N=(t-\tau) \delta$ if $\tau<t$ and zero otherwise, $(d-v) E(N)$ is the cost of defective items where $E(N)=\delta \mu Q^{2} / 2 P$, and $S S_{b}$ is the buyer's safety stock.

\section{Three-level supply chain models}

Gurnani (2001) considered the case where the supplier structures the quantity discount such that the buyers are encouraged to coordinate the timing of their orders (note that only the order timing is coordinated and that the order sizes could still be different). For the case of identical buyers, Gurnani (2001) showed that order coordination always leads to a reduction in the total system costs. However, for the general case of heterogeneous buyers, forcing order coordination on the buyers could result in an increase in the system costs. Later, Gurnani (2001) considered the case when the buyers place a combined (single) order with the supplier (referred to as "order consolidation"). For this case, the various buyers could be outlets at different geographical locations. In order to coordinate purchasing to take advantage of the quantity discount, a consolidated (bigger-sized) order is placed with the supplier. Upon receipt of the order at a centralized, it was assumed warehouse (say), the shipments are allocated to the outlets at the various locations. Finally, Gurnani (2001) considered the case of a 'multi-tier ordering hierarchy where only one of the buyers (could be a major wholesaler) places an order from the supplier directly. The remaining buyers, in turn, place orders only from the major buyer. In such an ordering hierarchy, the supplier benefits since he deals with only one buyer and transactions-related costs are therefore lower.

Munson and Rosenblatt (2001) investigated a supply chain that consists of a supplier, a vendor (manufacturer), and a buyer (retailer). The buyer determines the order quantity 
using the economic order quantity (EOQ) model. The vendor offers quantity discounts which it obtains from its supplier and offers to the retailer to generate cost savings for itself. The vendor's lot size is an integer multiplier of the buyer's order quantity, and that of the supplier is an integer multiplier of that of the vendor.

Khouja (2003b) extended the work of Munson \& Rosenblatt (2001) where he formulated and solve a three-stage, multi-customer, non-serial, supply chain inventory model, with multiple firms at each stage and a firm can supply two or more customers. He dealt with three coordination mechanisms, which are: (1) Equal cycle time, (2) Integer-multiplier at each stage, and and (3) Integer powers of two multipliers at each firm. Khouja (2003b) developed a supply chain cost for each case.

Lee (2005) considered a vendor (manufacturer), a buyer inventory control problem where the manufacturer orders raw materials from the supplier, then, through its production processes, converts the raw materials to finished products, and finally delivers the finished goods to the buyer. Six costs incurred in this supply chain, which are raw material ordering cost and holding cost, manufacturer's production setup cost and its finished goods holding cost, and buyer's inventory ordering cost and holding cost. Lee's objective was to develop an economic lot size model to minimize the integrated supply chain costs, while simultaneously taking the six costs above into accounts.

Lee and Moon (2006) developed inventory models for the three level supply chain; i.e., a supplier, a vendor (warehouse), and a buyer (retailer). The focus of their problem was determining the optimal integer multiple $\lambda$. of time interval, time interval between successive setups and orders in the coordinated inventory model. Lei et al. (2006) studied the channel coordination policies for a supply chain process involving a vendor (supplier), a buyer and a third party transportation partner. The transporter is assumed to have an operation cost structure similar to the one under a distribution service contract of the business case that motivated our study. That is, the transporter pays for a fixed (e.g., the packaging cost) and variable transportation cost for every order that the buyer places. They also assumed that the supplier controls the selling price to the buyer, pays for the shipping cost (i.e., the free-onboard contract with buyer), where the transporter charges supplier a shipping rate, be responsible for transporting the product from the supplier to the buyer, and bears his/her own operation cost, $a+b Q$, per order/ shipment, where parameter $a$ stands for the fixed cost per shipment (e.g., value-added services per order processed, insurance per trip, and truck driver's cost, etc) and parameter $b$ stands for the unit shipping variable cost (e.g., mileage cost and truck usage, etc). The market demand, $D(p)$, is assumed to be a commonly used decreasing convex function of buyer's selling price, $p$. The joint profit function was written as

$$
\begin{gathered}
\Pi_{s c}=\left(c_{b}-c_{t}-c_{v}\right) D(p)-\frac{A_{v} D(p)}{Q}-h_{v} \frac{Q}{2}+\left(c_{t}-b\right) D(p)-a \frac{D(p)}{Q} \\
+\left(p-c_{b}\right) D(p)-\frac{A_{b} D(p)}{Q}-h_{b} \frac{Q}{2}
\end{gathered}
$$

Defining $c_{t}$ as the average shipping rate charged by the transporter (as the transporter's decision variable), and $c_{t}>b+a / Q$, where transporter's operation cost per order is assumed 
to be $a+b Q$. The other parameters are $c_{b}\left(c_{v}\right)$ the buyer's (vendor's) unit purchasing price $\left(c_{v}<c_{b}<p\right)$ from the vendor (as the supplier's decision variable), $A_{b}\left(A_{v}\right)$ the buyer's (vendor's) fixed cost per order (setup), and $h_{b}\left(h_{v}\right)$ the buyer's (vendor's) unit holding cost per year. The market selling price that maximizes this channel joint yearly profit is $p^{*}$.

Jaber et al. (2006b) proposed a three-level (supplier-manufacturer-retailer) supply chain model with a profit sharing mechanism to maximize the supply chain profit. In the model, all-unit price discounts scheme is used to coordinate the order quantities among the supply chain levels and the demand at the retailer's end is assumed to be price dependent. To enhance co-ordination in the supply chain, two profit sharing scenarios are investigated. The semi-liberal scenario is based on increasing the quantity discount in order to generate more demands with which the most powerful player in the chain will get the highest fraction of additional profits. However, a strict mechanism is suggested to rectify the first scenario by dividing coordination profits based on equal return on investments. The supply chain profit function is the sum of players profit functions of the supplier, the vendor (manufacturer), and the buyer. The mathematical programming problem could then be written as

Maximize $Z=\Pi_{b}\left(Q, d_{b}\right)+\Pi_{v}\left(Q, d_{b}, d_{v}, \lambda_{v}\right)+\Pi_{s}\left(Q, d_{b}, d_{v}, \lambda_{v}, \lambda_{s}\right)$

Subject to:

$$
\begin{gathered}
\lambda_{s}, \lambda_{v} \geq 1 \\
d_{s}, d_{v}, d_{b} \geq 0 \\
d_{s} \leq p_{s}-c_{s} \\
d_{v} \leq p_{v}-\left(p_{s}-d_{s}\right) \\
d_{b} \leq p_{b}-\left(p_{v}-d_{v}\right) \\
Q>0
\end{gathered}
$$

Where the unit profit functions of the buyer, vendor and supplier respectively are

$$
\begin{gathered}
\Pi_{b}\left(Q, d_{b}\right)=\left(p_{b}-d_{b}\right) f\left(d_{b}\right)-\frac{A_{b} f\left(d_{b}\right)}{Q}-c_{b} f\left(d_{b}\right)-h_{b} \frac{Q}{2} \\
\Pi_{v}\left(Q, d_{b}, d_{v}, \lambda_{v}\right)=\left(p_{v}-c_{v}-d_{v}\right) f\left(d_{b}\right)-\frac{A_{v} f\left(d_{b}\right)}{\lambda_{v} Q}-h_{v}\left(\lambda_{v}-1\right) \frac{Q}{2} \\
\Pi_{s}\left(Q, d_{b}, d_{v}, d_{s}, \lambda_{v}, \lambda_{s}\right)=\left(p_{s}-c_{s}-d_{s}\right) f\left(d_{b}\right)-\frac{A_{s} f\left(d_{b}\right)}{Q \lambda_{v} \lambda_{s}} \\
-h_{s} \frac{Q}{2} \lambda_{v}\left(\lambda_{s}-1\right)
\end{gathered}
$$


And $i=s, v, b$ (supplier, vendor, buyer), $c_{i}$ is the procurement cost per unit for player $i, \tilde{p}_{i}$ is the non-discounted selling price for player $i, p_{i}$ is the selling price for player $i, d_{i}$ is the discount in price offered by player $i$ to $j$ where $i \neq j, h_{i}$ is the holding cost for player $i$, $f\left(d_{b}\right)$ is the annual demand rate measured from the end side of the chain, assumed to be a linear function of the discount rate, $f\left(d_{b}\right)=D_{0}+D_{1} d_{r}$, where $d_{b}=0$ means that the retailer is offering no price discounts to customers, and its demand rate shall remain at initial value $D_{0}$, i.e. $f(0)=D_{0}, A_{i}=$ set-up/order cost per cycle for player $i, Q$ is the order quantity for player $i$, and $\lambda_{i}$ is an integer multiplier to adjust the order quantity of player $i$ to that of $j$ where $i \neq j$. Jaber et al. (2006b) assumed a single product case, no shortages to occur, zero lead-time, perfect quality items, and infinite planning horizon. We also assume that demand is price dependent and the cost parameters do not vary over time.

Banerjee et al. (2007) develop an integrated inventory model for coordinating the procurement of input materials, albeit in somewhat of a limited way, with the production schedule, which, in turn, is linked to the product distribution and delivery plan. They adopted the concept of integer lot size factors as potentially effective mechanisms for establishing linkages among inventories at various echelons of the supply chain for achieving coordination. The aggregate total supply chain cost per time unit for the manufacturing (vendor), retail (buyer) and the pre-production (suppler) supply stages of the entire chain was given as

$$
T C_{s c}\left(Q, \lambda_{v}, \lambda_{s}\right)=\frac{D}{Q}\left[A_{b}+\frac{1}{\lambda_{v}}\left(A_{v}+A_{s} \lambda_{s}\right)\right]+\frac{Q}{2}\left\{h_{b}+h_{v}\left[\left(2-\lambda_{v}\right) \frac{D}{P}+\lambda_{v}-1\right]+\frac{\lambda_{v} D h_{s}}{P \lambda_{s}}\right\}
$$

Where $A_{i}, h_{i}(i=s, v, b)$, and $\lambda_{i}(i=s, v)$ are as defined above (Jaber et al. 2006b), $D=\sum_{i=1}^{n} D_{i}$ is the aggregated demand rate at the ends of the buyers, $P$ is the production rate $(P>D)$, and $Q=\sum_{i=1}^{n} q_{i}$ is the total units delivered to buyers. Each input materials bundle is delivered to the production facility in $\lambda_{S}$ (a positive integer) equally split lots. It is clear that, consistent with the JIT approach, $\lambda_{v} Q / \lambda_{S}$ units of the composite materials input are delivered $L$ times at regular intervals during each production cycle. The optimal values of $Q, \lambda_{v}$, and $\lambda_{s}$ were given as

$$
\begin{gathered}
Q=\sqrt{\frac{2 D\left[A_{b}+\left(1 / \lambda_{v}\right)\left(A_{v}+A_{s} \lambda_{s}\right)\right]}{h_{b}+h_{v}\left\{\left[\left(2-\lambda_{v}\right) D / P\right]+\lambda_{v}-1\right\}+\lambda_{v} D h_{s} / P \lambda_{s}}} \\
\lambda_{v}=\frac{1}{Q} \sqrt{\frac{2 D\left(A_{v}+A_{s} \lambda_{s}\right)}{h_{v}(1-D / P)+h_{s} D / P \lambda_{s}}} \\
\lambda_{s}=\lambda_{v} Q \sqrt{\frac{h_{s}}{2 P A_{s}}}
\end{gathered}
$$




\section{Four-level or more supply chain models}

Pourakbar et al. (2007) considered an integrated four-stage supply chain system, incorporating one supplier, multiple producers, multiple distributors multiple retailers. The aim of this model is to determine order quantity of each stage (from its upstream) and shortage level of each stage (for its downstream) such that the total cost of the supply chain to be minimized. Their model is an extension of the work of Lee (2005) from a linear three stages supply network including producer, distributor and retailer to a four stages supply network by adding one supplier. The complexity of the problem necessitated the development of heuristic solution procedures based on Genetic Algorithm to solve this problem. The model was investigated for the three coordination mechanisms described in Khouja (2003b), which are: (1) Equal cycle time, (2) cycle time at each stage of the chain is an integer multiplier of the cycle time of the adjacent downstream stage, and (3) the cycle time of each firm was an integer powers of two multiplies of a basic cycle time. Pourakbar et al. (2007) assumed a single product when buyers' shortages are backlogged.

Cárdenas-Barrón (2007) extended the work of Khouja's (2003b) three-stage supply chain by presenting an n-stage-multi-customer supply chain inventory model. He solve the cost function applying the algebraically (Grubbström \& Erdem, 1999). Cárdenas-Barrón (2007) selects the equal cycle time coordination mechanism for two reasons: the first one is that this Mechanism is the most simple and the second one is because our main purpose is to develop a useful supply chain model that can be taught without the use of calculus. He limited his mathematics and numerical examples to a 4-level supply chain (supplier-, where he assumed a single product. The total supply chain cost was of the form

$$
T C_{s C}=T\left\{\frac{V D h_{n}+\sum_{i=1}^{n-1}\left[\left(h_{i-1}+h_{i}\right) \sum_{j} D_{i, j}^{2} Y\right]}{2 V}\right\}+\frac{1}{T} \sum_{i . j} A_{i, j} \text { for all } i, j
$$

Where $V$ is the product of all production rates for all companies in the supply chain, and $Y$ is the product of all production rates for all companies in the supply chain, except for company $j$ in stage $i$ as Khouja (2003b) stated, $A_{i, j}$ is the setup or ordering cost for a company $j$ at stage $i, D=\sum_{j=1}^{J_{1}} D_{1, j}=\sum_{j=1}^{J_{2}} D_{2, j}=\cdots=\sum_{j=1}^{J_{n-1}} D_{n-1, j}=\sum_{j=1}^{J_{n}} D_{n, j}, D$ is the total demand at each stage, being the same demand across stages, $J_{i}$ is the total companies at stage $i, h_{i-1}$ is the holding cost of raw material for a company $j$ at stage $i$, and $h_{i}$ is the holding cost of finished products for a company $j$ at stage $i$. The above cost function was minimized subject to $T>0$.

\section{Conclusion}

This chapter presented a review of quantitative models for centralised supply chain coordination. Although we do not claim that this review has exhausted all related articles, we have reviewed most significant models available in the literature between 1990 to mid 2007. The chapter classifies the existing literature on the centralised supply chain coordination into three groups: a) two-level supply chain, b) three-level supply chain, and c) four or more levels. With majority of publications being in the first group, it is noticeable that the general case of $n$-level (centralised) supply chain coordination has not been 
adequately investigated. Also, it can be seen that the literature has focused either on single item/multi level supply chain or on multi-item/two-level supply chain. There has not been any significant study on multi-item/multi-level supply chain coordination and this could well be another direction for future research. It was also noticed that the majority of the centralised supply chain coordination literature is based on deterministic models. In reality, stochastic supply chain is more likely to be the case as demand, lead time, quality, and price (among other things) are stochastic in nature. Another observation that emerged through this literature review is that, similar to classical inventory optimization, the existing literature takes a cost optimization approach. The problem with this approach is that such models assume most of the cost parameters (such as holding costs and ordering costs) are readily available. In reality, such parameters may not be easily determined; therefore, the validity of such cost functions is questionable. Instead, other quantitative and qualitative performance measures such as the coordination impact on the quality of the firm's relationship with its suppliers, or the effect of such coordination on streamlining the business process in each player's organization should be considered.

\section{References}

Abad, P.L. \& Jaggi, C.K. (2003). A joint approach for setting unit price and the length of the credit period for a seller when end demand is price sensitive. International Journal of Production Economics, 83(2), 115-122.

Affisco, J.F.. Paknejad, M.J. \& Nasri, F. (1993). A comparison of alternative joint vendorpurchaser lot-sizing models. International Journal of Production Research, 31(11), 2661 $-2676$.

Balkhi, Z.T. (1999). On the global solution to an integrated inventory system with general time varying demand, production and deterioration rates. European Journal of Operational Research, 114 (1), 29-37.

Banerjee, A., (1986). A joint economic lot size model for purchaser and vendor. Decision Sciences, 17 (3), 292-311.

Banerjee, A., Kim, S.-L. \& Burton, J. (2007). Supply chain coordination through effective multi-stage inventory linkages in a JIT environment. International Journal of Production Economics, 108(1-2), 271-280.

Ben-Daya, M. \& Hariga, M. (2004). Integrated single vendor single buyer model with stochastic demand and variable lead time. International Journal of Production Economics, 92(1), 75-80.

Ben-Daya, M., Darwish, M. \& Ertogral, K. (2008). The joint economic lot sizing problem: Review and extensions. European Journal of Operational Research, 185(2), 726-742.

Boyaci, T. \& Gallego, G. (2002). Coordinating pricing and inventory replenishment policies for one wholesaler and one or more geographically dispersed retailers. International Journal of Production Economics, 77(2), 95-111.

Cárdenas-Barrón, L.E. (2007). Optimizing inventory decisions in a multi-stage multicustomer supply chain: A note. Transportation Research Part E: Logistics and Transportation Review, 43(5), 647-654.

Chen, F., Federgruen, A. \& Zheng, Y.-S. (2001). Coordination mechanisms for a distribution system with one supplier and multiple retailers. Management Science, 47(5), 693-708.

Chen, J.M. \& Chen, T.H. (2005c). Effects of joint replenishment and channel coordination for managing multiple deteriorating products in a supply chain. Journal of the Operational Research Society, 56 (10), 1224-1234. 
Chen, J.M. \& Chen, T.H. (2007). The profit-maximization model for a multi-item distribution channel. Transportation Research Part E: Logistics and Transportation Review, 43(4), 338-354.

Chen, J.M. \& Chen, T.H. (2005a). The multi-item replenishment problem in a two-echelon supply chain: the effect of centralization versus decentralization. Computers $\mathcal{E}$ Operations Research, 32(12), 3191-3207.

Chen, L.H. \& Kang, F.S. (2007). Integrated vendor-buyer cooperative inventory models with variant permissible delay in payments. European Journal of Operational Research, 183(2), 658-673.

Chen, T.H. \& Chen, J.M. (2005b). Optimizing supply chain collaboration based on joint replenishment and channel coordination. Transportation Research Part E: Logistics and Transportation Review, 41(4), 261-285.

Comeaux, E.J. \& Sarker, B.R. (2005). Joint optimization of process improvement investments for supplier-buyer cooperative commerce. Journal of the Operational Research Society, 56(11), 1310-1324.

Crowther, J. (1964). Rationale of quantity discounts. Harvard Business Review, 42(2), 121-127.

Dolan, R.J. (1987). Quantity discounts: managerial issues and research opportunities. Marketing Science, 6(1), 1-22.

El Saadany, A.M.A. \& Jaber, M.Y. (2008). Coordinating a two-level supply chain with production interruptions to restore process quality. Computers $\mathcal{E}$ Industrial Engineering, 54(1), 95-109.

Ertogral, K., Darwish, M. \& Ben-Daya, M. (2007). Production and shipment lot sizing in a vendor-buyer supply chain with transportation cost. European Journal of Operational Research, 176(3), 1592-1606.

Friedman, J.W. (1986). Game Theory with Application to Economics. Oxford University Press, New York.

Goyal, S.K. \& Gupta, Y.P. (1989). Integrated inventory models: The buyer-vendor coordination. European Journal of Operational Research, 41(3), 261-269.

Goyal, S.K. (1977). An integrated inventory model for a single supplier-single customer problem. International Journal of Production Research, 15(1), 107 - 111.

Goyal, S.K. (1988). A joint economic lot size model for purchaser and vendor: A comment. Decision Sciences, 19(1), 236-241.

Goyal, S.K. (1995). A one-vendor multi-buyer integrated inventory model: A comment. European Journal of Operational Research, 82(1), 209-210.

Goyal, S.K. Huang, C-K, \& Chen K-C, (2003). A simple integrated production policy of an imperfect item for vendor and buyer. Production Planning $\mathcal{E}$ Control, 14(7), 596 - 602.

Grubbström, R.W. \& Erdem, A. (1999). The EOQ with backlogging derived without derivatives. International Journal of Production Economics, 59(1-3), 529-530.

Gurnani, H. (2001). A study of quantity discount pricing models with different ordering structures: Order coordination, order consolidation, and multi-tier ordering hierarchy. International Journal of Production Economics, 72(3), 203-225.

Hill, R.M. (1997). The single-vendor single-buyer integrated production-inventory model with a generalised policy. European Journal of Operational Research, 97(3), 493-499.

Hoque, M.A. (2007). An alternative model for integrated vendor-buyer inventory under controllable lead time and its heuristic solution. International Journal of Systems Science, 38(6), $501-509$.

Huang, C.K. (2002). An integrated vendor-buyer cooperative inventory model for items with imperfect quality. Production Planning \& Control, 13(4), 355 - 361. 
Huang, C.K. (2004). An optimal policy for a single-vendor single-buyer integrated production-inventory problem with process unreliability consideration. International Journal of Production Economics, 91(1), 91-98.

Jaber, M.Y. \& Osman, I.H. (2006). Coordinating a two-level supply chain with delay in payments and profit sharing. Computers $\mathcal{E}$ Industrial Engineering, 50(4), 385-400.

Jaber, M.Y., Nuwayhid, R.Y. \& Rosen, M.A. (2006a). A thermodynamic approach to modelling the economic order quantity. Applied Mathematical Modelling, 30(9), 867883.

Jaber, M.Y., Nuwayhid, R.Y. \& Rosen, M.A. (2004). Price-driven economic order systems from a thermodynamic point of view. International Journal of Production Research, 42(24), 5167-5184.

Jaber, M.Y., Osman, I.H. \& Guiffrida, A. L. (2006b). Coordinating a three-level supply chain with price discounts, price dependent demand, and profit sharing. International Journal of Integrated Supply Management, 2(1-2), 28 - 48.

Jamal, A.M.M., Sarker, B.R. \& Wang, S. (2000). Optimal payment time for a retailer under permitted delay of payment by the wholesaler. International Journal of Production Economics, 66(1), 59-66.

Joglekar, P., \& Tharthare, S. (1990). The individually responsible and rational decision approach to economic lot sizes for one vendor and many purchasers. Decision Sciences, 21(3), 492-506.

Khouja, M. (2003a). The impact of quality considerations on material flow in two-stage inventory systems. International Journal of Production Research, 41(7), 1533-1547.

Khouja, M. (2003b). Optimizing inventory decisions in a multi-stage multi-customer supply chain, Transportation Research Part E: Logistics and Transportation Review, 39(3), $193-$ 208.

Khouja, M. (2005). The use of minor setups within production cycles to improve product quality and yield. International Transactions in Operations Research, 12(4), 403-416.

Kohli, R. \& Park, H. (1994). Coordinating buyer-seller transactions across multiple products. Management Science, 40(9), 1145-1150.

Lee, J.H. \& Moon, I.K. (2006). Coordinated inventory models with compensation policy in a three level supply chain. Lecture Notes in Computer Science, 3982, 600-609.

Lee, W. (2005). A joint economic lot-size model for raw material ordering, manufacturing setup, and finished goods delivering. Omega, 33(2), 163-174.

Lei, L., Wang, Q. \& Fan, C. (2006). Optimal business policies for a supplier-transporterbuyer channel with a price-sensitive demand. Journal of the Operational Research Society, 57(3), 281-289.

Li, S.X., Huang, Z. \& Ashley, A. (1995). Seller-buyer system co-operation in a monopolistic market. Journal of the Operational Research Society, 46(12), 1456-1470.

Li, X. \& Wang, Q. (2007). Coordination mechanisms of supply chain systems. European Journal of Operational Research, 179(1), 1-16.

Lin, C. \& Lin, Y. (2004). A joint EOQ model for supplier and retailer with deteriorating items. Asia Pacific Journal of Operational Research, 21(2), 163-178.

Lin, C. \& Lin, Y. (2007). A cooperative inventory policy with deteriorating items for a twoechelon model. European Journal of Operational Research, 178(1), 92-111

Lu, L. (1995). A one-vendor multi-buyer integrated inventory model. European Journal of Operational Research, 81(2), 312-323.

Maloni, M.J. \& Benton, W.C. (1997). Supply chain partnerships: Opportunities for operations research. European Journal of Operational Research, 101(3), 419-429. 
Munson, C. L. \& Rosenblatt, M. J. (1998). Theories and realities of quantity discounts: An exploratory study. Production and Operations Management, 7(4), 352-369.

Munson, C. L. \& Rosenblatt, M. J. (2001). Coordinating a three-level supply chain with quantity discounts. IIE Transactions, 33(5), 371-384.

Nachiappan, S.P., Jawahar, N. \& Ganesh, M. (2006). Pricing in a vendor managed inventory system. International Journal of Logistics Systems and Management, 2(1), 19-37.

Pan, J. C.-H. \& Yang, M.-F. (2008). Integrated inventory models with fuzzy annual demand and fuzzy production rate in a supply chain. International Journal of Production Research 46(3), 753-770

Pan, J. C.-H. \& Yang, J.S. (2002). A study of an integrated inventory with controllable lead time. International Journal of Production Research, 40(5), 1263-1273.

Piplani, R. \& Viswanathan, S. (2004). Supply chain inventory co-ordination through multiple, common replenishment epochs and selective discount. International Journal of Logistics : Research and Applications, 7(2), 109 - 118.

Porteus, E.L. (1986). Optimal lot sizing, process quality improvement and setup cost reduction. Operations Research, 34(1), 137-144.

Pourakbar, M., Farahani, Z. R. \& Asgari, N. (2007). A joint economic lot-size model for an integrated supply network using genetic algorithm. Applied Mathematics and Computation, 189(1), 583-596.

Ritvirool, A. \& Ferrell Jr., W.G. (2007). The effect on inventory of cooperation in singlevendor, single-buyer systems with quality considerations. International Journal of Operational Research, 2(3), 338-356.

Salameh, M.K. \& Jaber, M.Y. (2000). Economic production quantity model for items with imperfect quality. International Journal of Production Economics, 64(1-3), 59-64.

Sarmah, S.P., Acharya, D. \& Goyal, S.K. (2006). Buyer vendor coordination models in supply chain management. European Journal of Operational Research, 175(1), 1-15.

Sarmah, S.P., Acharya, D. \& Goyal, S.K. (2007). Coordination and profit sharing between a manufacturer and a buyer with target profit under credit option. European Journal of Operational Research, 182(3), 1469-1478.

Sharafali, M. \& Co, H.C. (2000). Some models for understanding the cooperation between the supplier and the buyer. International Journal of Production Research, 38(15), 3425 3449.

Sheen, G.J. \& Tsao, Y.C. (2007). Channel coordination, trade credit and quantity discounts for freight cost. Transportation Research Part E: Logistics and Transportation Review, 43(2), 112-128.

Siajadi, H., Ibrahim, R. N., Lochert, P. B. \& Chan, W. M. (2005). Joint replenishment policy in inventory-production systems. Production Planning \& Control, 16(3), 255 - 262.

Siajadi, H., Ibrahim, R.N. \& Lochert, P.B. (2006a). Joint economic lot size in distribution system with multiple shipment policy. International Journal of Production Economics, 102(2), 302-316.

Siajadi, H., Ibrahim, R. N. \& Lochert, P.B. (2006b),. A single-vendor multiple-buyer inventory model with a multiple-shipment policy. The International Journal of Advanced Manufacturing Technology, 27(9-10), 1030 - 1037.

Srinivas, C. \& Rao, C.S.P. (2007). Optimisation of supply chains for single vendormultibuyer consignment stock policy under controllable lead time using genetic algorithm. International Journal of Manufacturing Research, 2(2), 243-262.

Thomas, D.J. \& Griffin, P.M. (1996).Coordinated supply chain management. European Journal of Operational Research, 94(1), 1-15. 
Viswanathan, S. (1998). Optimal strategy for the integrated vendor-buyer inventory model. European Journal of Operational Research, 105(1), 38-42.

Viswanathan, S. \& Piplani, R. (2001). Coordinating supply chain inventories through common replenishment epochs. European Journal of Operational Research, 129(2), 277286.

Wee H. M. \& Yang, P.C. (2007). A mutual beneficial pricing strategy of an integrated vendor-buyers inventory system. The International Journal of Advanced Manufacturing Technology, 34(1-2), 179-187.

Wee, H.M., Yu, J.C.P. \& Wang, K.J. (2006). An integrated production-inventory model for deteriorating items with imperfect quality and shortage backordering considerations. Lecture Notes in Computer Science, 3982, 885-897.

Woo, Y.Y., Hsu, S.L. \& Wu, S. (2000). Order processing cost reduction in a joint vendorbuyer inventory system via the application of information technology. The Engineering Economist, 45(4), 350 - 365

Woo, Y.Y., Hsu, S.L. \& Wu, S. (2001). An integrated inventory model for a single vendor and multiple buyers with ordering cost reduction. International Journal of Production Economics, 73(3), 203-215.

Wu, K.S. \& Ouyang, L.-Y. (2003). An integrated single-vendor single-buyer inventory system with shortage derived algebraically. Production Planning $\mathcal{E}$ Control, 14(6), 555-561.

Yang, P.C., Wee, H. M. \& Yang, H. J. (2007). Global optimal policy for vendor-buyer integrated inventory system within just in time environment. Journal of Global Optimization, 37(4), 505 - 511.

Yang, P. \& Wee, H. (2003). Optimal strategy in vendor-buyer alliances with quantity discount. International Journal of Computer Integrated Manufacturing, 16(6), 455-463.

Yang, P.C. \& Wee, H.M. (2006a). A collaborative inventory system with permissible delay in payment for deteriorating items. Mathematical and Computer Modelling, 43(3-4), 209221.

Yang, P.C. \& Wee, H.M. (2006b). Integrated vendor-buyers system with quantity-discount and identical replenishment cycle time policy. International Journal of Services Operations and Informatics, 1(4), 393-409.

Yao, M.J. \& Chiou, C.C. (2004). On a replenishment coordination model in an integrated supply chain with one vendor and multiple buyers. European Journal of Operational Research, 159(2), 406-419.

$\mathrm{Yu}, \mathrm{Y} ., \mathrm{Chu}, \mathrm{F}$. \& Chen, H. (2006). On improving an integrated inventory model for a single vendor and multiple buyers with a relaxed material ordering cycle policy. Journal of Systems Science and Systems Engineering, 15(3), 298-313.

Yugang, Y., Liang, L. \& Huang, G.Q. (2006). Leader-follower game in vendor-managed inventory system with limited production capacity considering wholesale and retail prices. International Journal of Logistics Research and Applications, 9(4), 335 350.

Zhang, T., Liang, L.; Yu, Y. \& Yu, Y. (2007). An integrated vendor managed inventory model for a two-echelon system with order cost reduction. International Journal of Production Economics, 109(1-2), 241-253.

Zhou, Y.W. \& Wang, S.D. (2007). Optimal production and shipment models for a singlevendor-single-buyer integrated system. European Journal of Operational Research, 180(1), 309-328. 


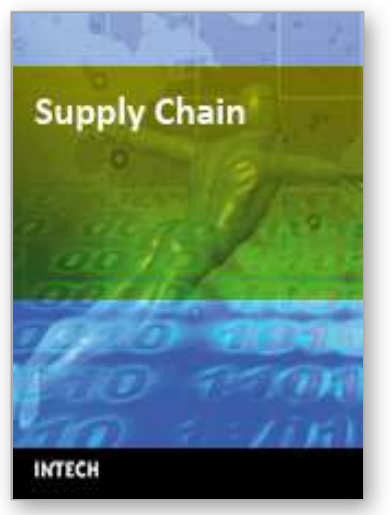

\author{
Supply Chain \\ Edited by Vedran Kordic
}

ISBN 978-3-902613-22-6

Hard cover, 568 pages

Publisher I-Tech Education and Publishing

Published online 01, February, 2008

Published in print edition February, 2008

Traditionally supply chain management has meant factories, assembly lines, warehouses, transportation vehicles, and time sheets. Modern supply chain management is a highly complex, multidimensional problem set with virtually endless number of variables for optimization. An Internet enabled supply chain may have justin-time delivery, precise inventory visibility, and up-to-the-minute distribution-tracking capabilities. Technology advances have enabled supply chains to become strategic weapons that can help avoid disasters, lower costs, and make money. From internal enterprise processes to external business transactions with suppliers, transporters, channels and end-users marks the wide range of challenges researchers have to handle. The aim of this book is at revealing and illustrating this diversity in terms of scientific and theoretical fundamentals, prevailing concepts as well as current practical applications.

\title{
How to reference
}

In order to correctly reference this scholarly work, feel free to copy and paste the following:

Mohamad Y. Jaber and Saeed Zolfaghari (2008). Quantitative Models for Centralised Supply Chain Coordination, Supply Chain, Vedran Kordic (Ed.), ISBN: 978-3-902613-22-6, InTech, Available from: http://www.intechopen.com/books/supply_chain/quantitative_models_for_centralised_supply_chain_coordinati on

\section{INTECH}

open science | open minds

\author{
InTech Europe \\ University Campus STeP Ri \\ Slavka Krautzeka 83/A \\ 51000 Rijeka, Croatia \\ Phone: +385 (51) 770447 \\ Fax: +385 (51) 686166 \\ www.intechopen.com
}

\author{
InTech China \\ Unit 405, Office Block, Hotel Equatorial Shanghai \\ No.65, Yan An Road (West), Shanghai, 200040, China \\ 中国上海市延安西路65号上海国际贵都大饭店办公楼405单元 \\ Phone: +86-21-62489820 \\ Fax: $+86-21-62489821$
}


(C) 2008 The Author(s). Licensee IntechOpen. This chapter is distributed under the terms of the Creative Commons Attribution-NonCommercialShareAlike-3.0 License, which permits use, distribution and reproduction for non-commercial purposes, provided the original is properly cited and derivative works building on this content are distributed under the same license. 